\title{
Application of Near-Field Emission Processing for Microwave Circuits under Ultra-Short Duration Perturbations
}

\author{
Yang Liu and Blaise Ravelo \\ IRSEEM (Institut de Recherche en Systèmes Electroniques Embarqués), EA 4353, \\ At the graduate school of engineering ESIGELEC, \\ Av. Galilée, BP 10024, 76801 Saint Etienne du Rouvray, France. \\ Tel.: +33 (0)232915971 \\ Fax: +33 (0)2 32915859 \\ *corresponding author, E-mail: yang.liudesigelec.fr, blaise.ravelo@yahoo.fr
}

\begin{abstract}
This paper deals with the processing method of electromagnetic (EM) near-field (NF) radiated by microwave circuits with transient pulse signals. Two different NF processing methods are proposed by applying the time-frequency approach. First, a computation method of NF/NF transform is presented. This enables to calculate the EM NF maps at different distances from the radiating circuit. The feasibility of NF/NF in both frequency- and time-domain is verified with experimental results. Then, NF processing based on NF emission model implemented in UWB frequency band is also examined in the second part of the paper. For that, the number of EM NF maps representing the large band model is reduced in order to simplify the model based on a set of dipole-array. The timedomain model is implemented by considering the convolution of the transient excitation signals and the UWB dipole-array model. This time-frequency model was validated with a planar microstrip device excited by microwave signal modulating $1.25-\mathrm{GHz}$-carrier and 0.5 GHz-bandwidth. The methods explored in this paper are particularly useful for the investigation of time-domain emissions for EMC applications by considering transient EM interferences (EMIs).
\end{abstract}

Keywords: Near-field (NF) processing, time-frequency method, time-domain, electromagnetic compatibility (EMC), plane wave spectrum (PWS), wide band emission model.

\section{Introduction}

With the emergence of the hybrid technology integrated with multifunction, the issues related to the electromagnetic interference (EMI) [1-9] and electromagnetic compatibility (EMC) [10-14] become a primary importance during the manufacturing of the electrical and electronic circuits. The incessant technological development is currently known with systems integrating more and more different hybrid functions in a confine space. As a matter of fact, the EMI and EMC can be an important malfunctioning source of various types of electronic printed circuit boards [4-8]. So, the EMC characterization according to the standard requirements needs to be taken into account during the design process of electronic circuits [10-14]. Nowadays, one of the most attractive breakthroughs concerns the nearfield (NF) couplings [15-23]. In addition, the determination of EM NF map is one of efficient ways in order to assure the reliability and safety of new electronic products [24-25]. So, measurement techniques and modelling methods of NF emitted by electronic systems were developed [26-27]. To study the influence of these unintentional NF emissions, susceptibility and immunity analyses were also realized [1823].

Nevertheless, most of EMC NF characterizations are carried out in frequency-domain [7][9][29-33]. However, as the operating data speed achieves currently several Gbits/s with millions of transistors switch simultaneously, the frequency-domain radiating EMC characterization seems to be insufficient. This is why the time-domain EMC analyses and modelling are required. Till now, in our knowledge, few studies have been done on EM radiated emissions modelling in the time-domain [35-45].

This explains why we are motivated to conduct the timefrequency method for the treatment of the EM NF emission. Two different processing methods are presented in this paper: (i) The NF/NF transform in the time-domain by using the plane wave spectrum (PWS) theory and (ii) a modelling of the NF radiation with dipole-array in the timedomain. The main part of this paper is about the NF/NF transform investigated which was firstly proposed in the frequency-domain [45]. Then, the continuation works in the time-domain is introduced in this paper [47]. The considered theory on the transient radiation of dipoles is presented in [49-62]. The principle of this method is mainly based on the plane wave spectrum (PWS) transform associated with the fast Fourier transform as introduced in [63-77]. We realize here a space-time computation method enabling to map the EM NF in a plane situated at certain distance of the given 2D NF data in time-domain as 
proposed in [63-67]. The calculation is based on the plane wave spectrum (PWS) theory combined with the FFT [68].

This paper is mainly divided in four main sections. Section 2 is focused on the application of the routine algorithm traducing the time-frequency NF/NF method under study [46-47]. Section 3 presents validation results illustrating the relevance of the NF processing. Section 4 is focused on the transposition of the EM NF emission modelling explored in [29-33] into time-domain. The originality of this section compared to the work done in [69] is stated. Finally, Section 5 is the conclusion of the paper.

\section{Presentation of the NF / NF transform in time domain}

The NF extraction method proposed in this paper is based on the PWS theory [71-76] combined with the plane wave propagation properties and FFT. The methodology of the computation method is detailed in this section. The theoretical approach is illustrated in the first subsection. Then, the calculation routine representing the method mechanisms will be offered. Finally, validation results are presented.

\subsection{Theoretical principle of the NF/NF extraction method [47]}

In this section, the theoretical principle of the timefrequency NF extraction method is introduced. The PWS theory is known as the formulation allowing to decompose any field as a sum of plane waves propagating in all directions. It is widely used for predicting the radiation for EMC application. By definition, any electric or magnetic (E- or $\mathrm{H}-$ ) fields in the rectangular coordinate system (Oxyz), the EM field vectors $\vec{E}\left(x, y, z_{0}\right)$ and $\vec{H}\left(x, y, z_{0}\right)$ can be decomposed as a sum of PWS 2D spectral components, which are respectively given mathematically by the following formulae [71-76]:

$$
\left\{\begin{array}{l}
\overrightarrow{P_{e}}\left(k_{x}, k_{y}\right)=\int_{-\infty}^{\infty} \int_{-\infty}^{\infty} \vec{E}\left(x, y, z_{0}\right) e^{j\left(k_{x} \cdot x+k_{y} \cdot y\right)} d x \cdot d y \\
\overrightarrow{P_{h}}\left(k_{x}, k_{y}\right)=\int_{-\infty}^{\infty} \int_{-\infty}^{\infty} \vec{H}\left(x, y, z_{0}\right) e^{j\left(k_{x} \cdot x+k_{y} \cdot y\right)} d x \cdot d y
\end{array}\right.
$$

As we can see, the PWS transform is similar to the 2D Fourier transform. It can be implemented with the 2D fast Fourier transform (FFT2) or the inverse 2D fast Fourier transform (IFFT2) defined preliminarily in Matlab. So that, the inverse PWS (IPWS) transform is given by:

$$
\left\{\begin{array}{l}
\vec{E}\left(x, y, z_{0}\right)=\frac{1}{4 \pi^{2}} \int_{-\infty}^{\infty} \int_{-\infty}^{\infty} \overrightarrow{P_{e}}\left(k_{x}, k_{y}\right) e^{-j\left(k_{x} \cdot x+k_{y} \cdot y\right)} d k_{x} \cdot d k_{y} \\
\vec{H}\left(x, y, z_{0}\right)=\frac{1}{4 \pi^{2}} \int_{-\infty}^{\infty} \int_{-\infty}^{\infty} \overrightarrow{P_{h}}\left(k_{x}, k_{y}\right) e^{-j\left(k_{x} \cdot x+k_{y} \cdot y\right)} d k_{x} \cdot d k_{y}
\end{array}\right.
$$

In the considered coordinate system $O x y z$, the wave vector can be decomposed with the unit vector $\left(\overrightarrow{u_{x}}, \overrightarrow{u_{y}}, \overrightarrow{u_{z}}\right)$ as:

$\vec{k}(f)=k_{x}(f) \overrightarrow{u_{x}}+k_{y}(f) \overrightarrow{u_{y}}+k_{z}(f) \overrightarrow{u_{x}}$,

In the frequency-domain, the wave vector module which is also called the wave number can be written as:

$$
k(f)=\sqrt{k_{x}^{2}(f)+k_{y}^{2}(f)+k_{z}^{2}(f)}=\frac{2 \pi}{\lambda(f)},
$$

with $\lambda(f)=c / f$, the propagating wavelength at the frequency $f$, where $c$ is the light speed in the certain medium. The PWS operation consists in the decomposition of the planar EM-field in its 2-D spectrum similar to FFT known with the Matlab instruction fft 2 . Thus, the properties of the plane wave propagation can be applied to the 2D EM field after the PWS transform. This proposed extraction technique is based on the combination of the plane wave property with the PWS transform. Let us denote that $\vec{E}\left(x, y, z_{d}\right)$ and $\vec{H}\left(x, y, z_{d}\right)$ the E- and H-field in the plane placed at the height $z=z_{d}$ above the radiation source plane. Therefore, their PWS can be finally written as:

$$
\left\{\begin{array}{l}
{\overrightarrow{p_{e}}}_{z=z_{d}}\left(k_{x}, k_{y}\right)={\overrightarrow{p_{e}}}_{z=z_{0}}\left(k_{x}, k_{y}\right) \cdot e^{-j k_{z}\left(z_{d}-z_{0}\right)} \\
\vec{p}_{h_{z=z_{d}}}\left(k_{x}, k_{y}\right)={\overrightarrow{p_{h}}}_{z=z_{0}}\left(k_{x}, k_{y}\right) \cdot e^{-j k_{z}\left(z_{d}-z_{0}\right)},
\end{array}\right.
$$

and the EM field can be carried out by using the inverse PWS transform:

$$
\left\{\begin{array}{l}
\vec{E}\left(x, y, z_{d}\right)=\operatorname{IPWS}\left[{\overrightarrow{p_{e}=z_{d}}}\left(k_{x}, k_{y}\right)\right] \\
\vec{H}\left(x, y, z_{d}\right)=\operatorname{IPWS}\left[{\overrightarrow{p_{h}}}_{z=z_{d}}\left(k_{x}, k_{y}\right)\right]
\end{array}\right.
$$

It is important to note that the PWS theory is fundamentally implemented in the frequency-domain. Meanwhile, for starting the processing, the EM field data recorded in the time-domain must be transported into the frequency-domain. To do this, we use the classical time-frequency operation with FFT. Then, after the application of the NF/NF PWS transform, we apply the IFFT in order to achieve the timedomain field at the different heights. Figure 1 explains the successive steps to carry out the NF/NF transform under study. 


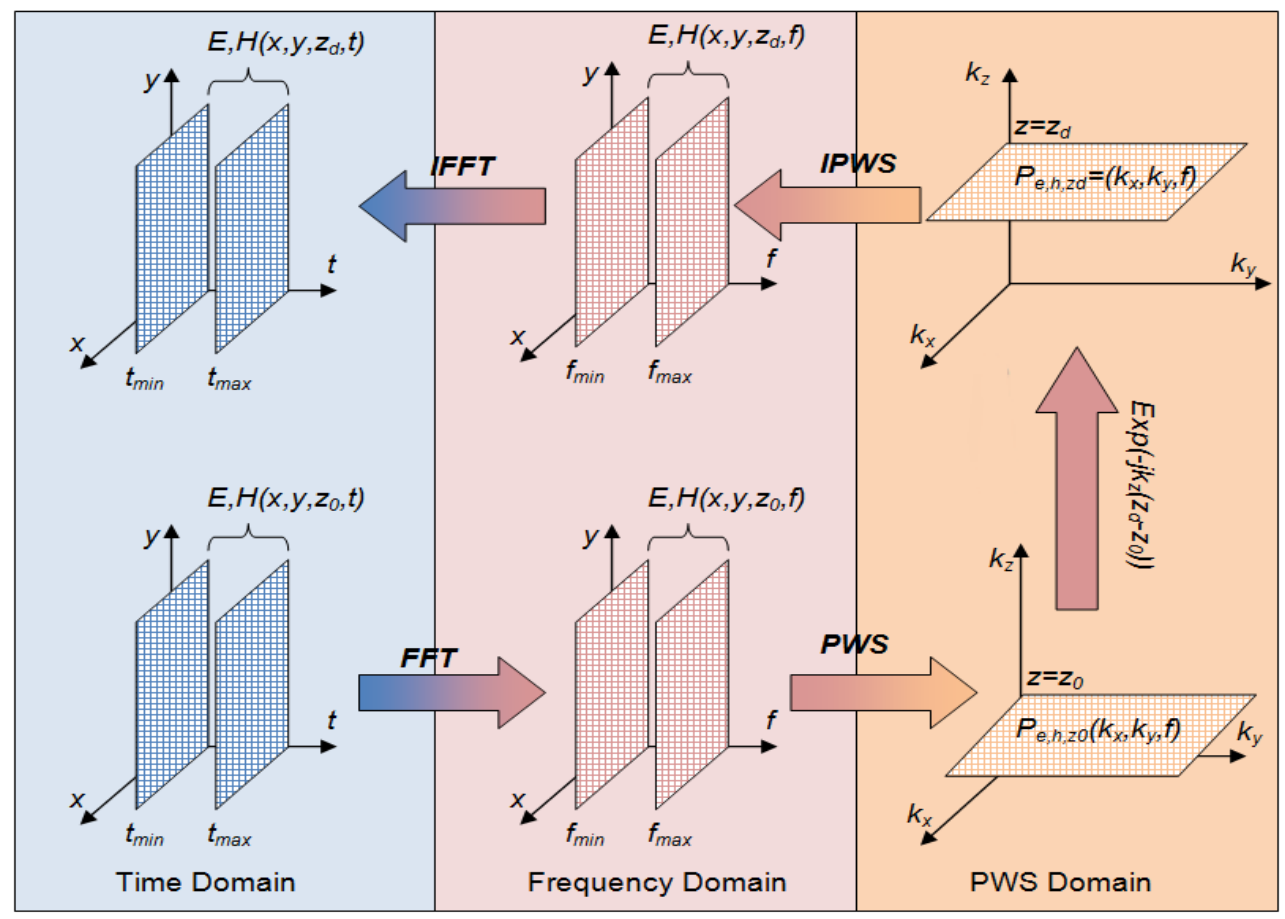

Figure 1: Different steps for extracting the EM field at different heights [47].

2.2. Flow method of the time-frequency NF/NF processing [47]

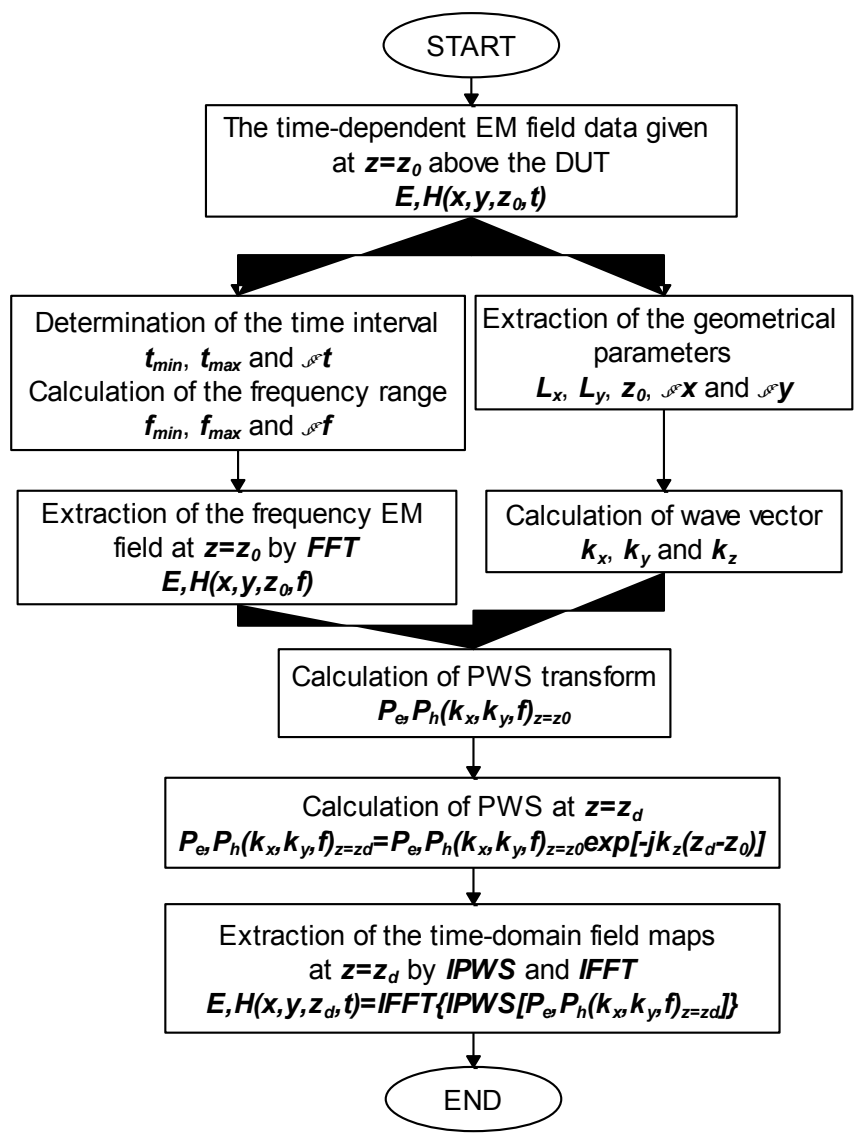

Figure 2: Routine process of the NF/NF transform in the time-domain [47].

The theoretical approach is clearly introduced in the previous section. In order to implement the investigated computational method, the working flow chart summarizes the proposed method with several steps, shown by Figure 2 . For further analysis, a Matlab program was realized with the algorithm in Figure 2 in order to validate our proposed extraction method.

\section{Validation results}

This section is depicted on the application of the routine process established previously. First, we analyse the results obtained in the frequency-domain from concrete devices based on the flow design shown in Figure 1. Then, we will examine the results with the algorithm illustrated by the flow chart shown in Figure 2.

\subsection{Analysis of the validation results in the frequency domain [46]}

This subsection is divided in three different paragraphs.

* The first one investigates the radiation of the set of EM dipoles placed randomly in the plane $z=0$.

* The second paragraph presents the feasibility of the method by deeming with a microstrip structure designed and simulated with HFSS 3D software from Ansoft ${ }^{\mathrm{TM}}$.

* The last paragraph focus is on the results from measurements carried out at the IRSEEM laboratory. 
Then, by using Matlab programs, we will demonstrate that the maps of the electric field in the planes positioned at different heights above the radiating structures can be expressed easily from the data recorded at a reference height, for example, placed at $z_{0}=2 \mathrm{~mm}$.

\subsubsection{Validation with analytical application}

To verify the relevance of the method proposed through analytical calculations proposed in Figure 1, we propose first, to study the radiation of a set of six elementary dipoles placed at different points $\mathrm{D}_{1 \ldots 6}$ in the horizontal plane as configured in Figure 3.
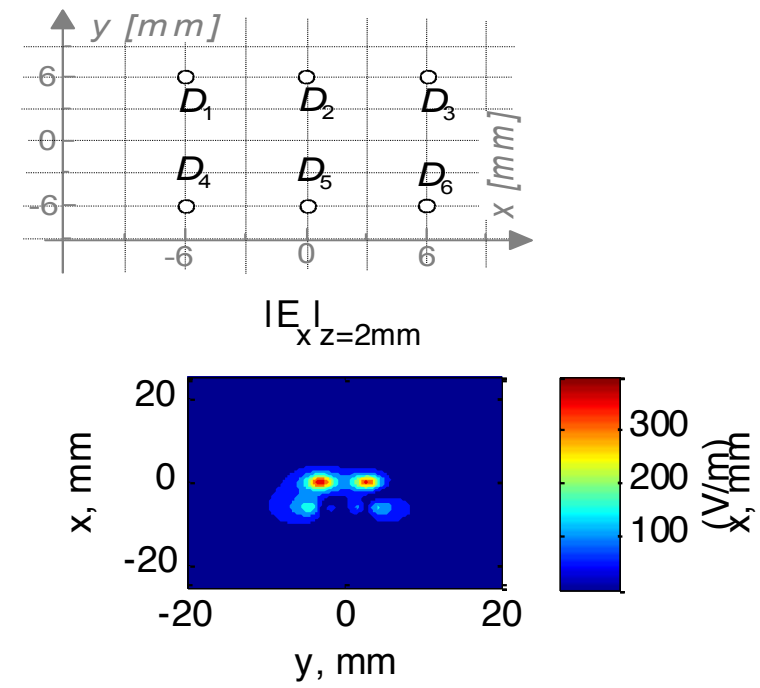

Figure 3: Configuration of the magnetic dipoles used for verification.

Each of ideal elementary magnetic dipoles are constituted by a circular metallic loop with $0.2 \mathrm{~mm}$ diameter and excited by a harmonic current with the magnitude of $I=1 \mathrm{~A}$ and the frequency of $f=3 \mathrm{GHz}$. By using the expressions of the Efield radiated by this set of dipoles, the E-field maps in the horizontal plane placed at $z=\{2 \mathrm{~mm}, 4 \mathrm{~mm}\}$ were calculated analytically.

Then, by considering the maps of $E_{x, y}(\mathrm{z}=2 \mathrm{~mm})$ shown in Figure 4, we extracted those ones in the planes placed at the arbitrarily chosen height $z=4 \mathrm{~mm}$. The comparison results are displayed in Figures 5. One can see that very good agreement between the results from the direct analytical calculations and those from the PWS method is realized.

Figure 4: Maps of the E-field at $\mathrm{z}=2 \mathrm{~mm}$.
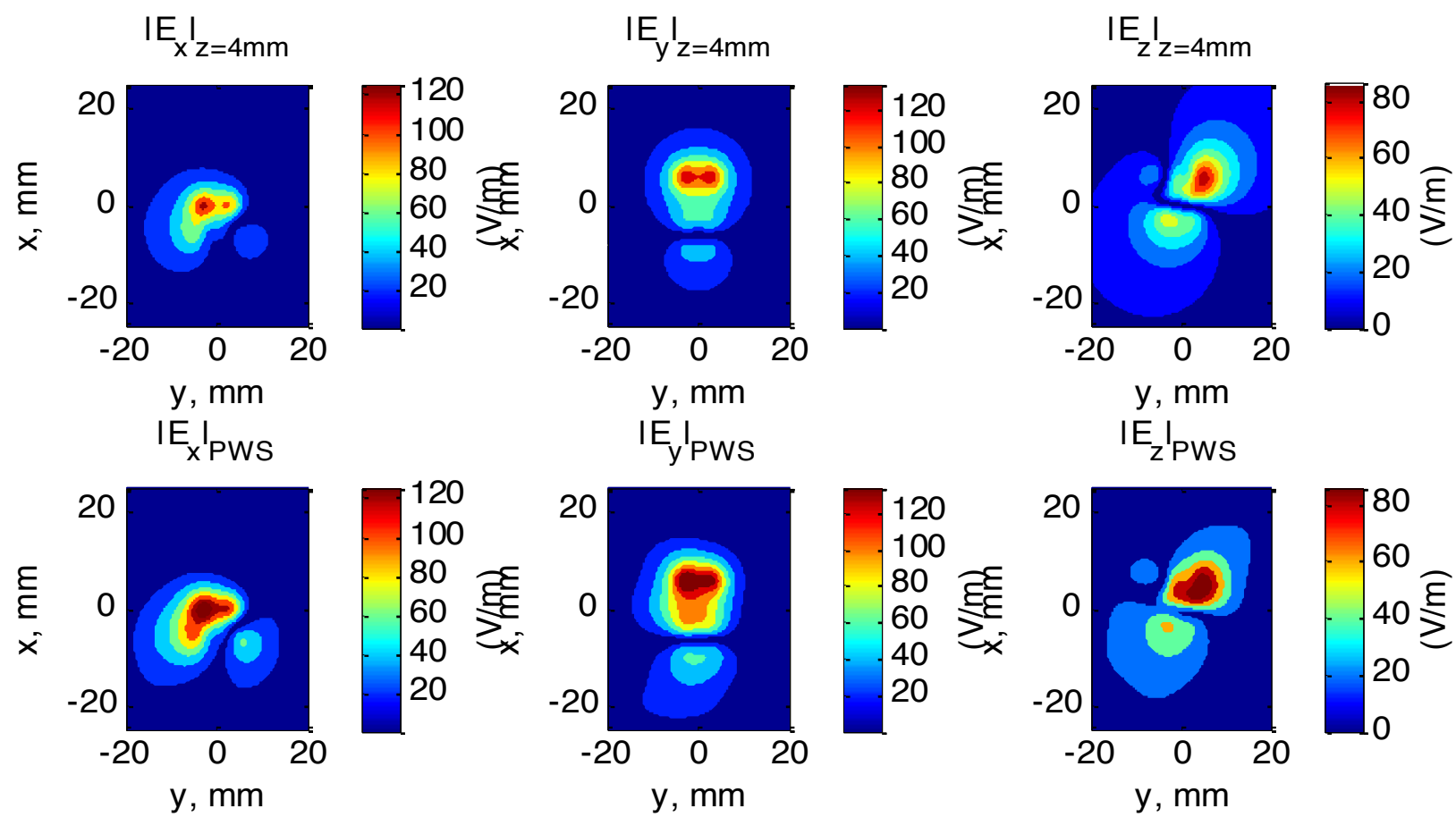

Figure 5: Comparisons of the E-field maps computed directly from the analytical defintion and from the PWS method proposed at $\mathrm{z}=4 \mathrm{~mm}$. 
3.1.2. Validation with microstrip device NF radiation fullwave simulations

In this paragraph, we apply the PWS NF/NF method with structure simulated with the 3D EM simulation commercial software HFSS. More concrete validation of the NF/NF transform was also realized by considering the microstrip structure presented in Figure 6. After HFSS simulations set with operating frequency $f=2 \mathrm{GHz}$, we mapped the E-field in the planes placed at $\{z=2 \mathrm{~mm}, z=5 \mathrm{~mm}, z=7 \mathrm{~mm}\}$ above the structure. Then, by considering the result recorded at $z_{0}=$ $2 \mathrm{~mm}$ (see Figure 7), we have extracted the E-fields at $\{z=5$ $\mathrm{mm}, z=7 \mathrm{~mm}$. So, one gets the results shown in Figures 8 and Figures 9. Once again, the maps from the PWS method established are in good correlation with the results simulated with HFSS.

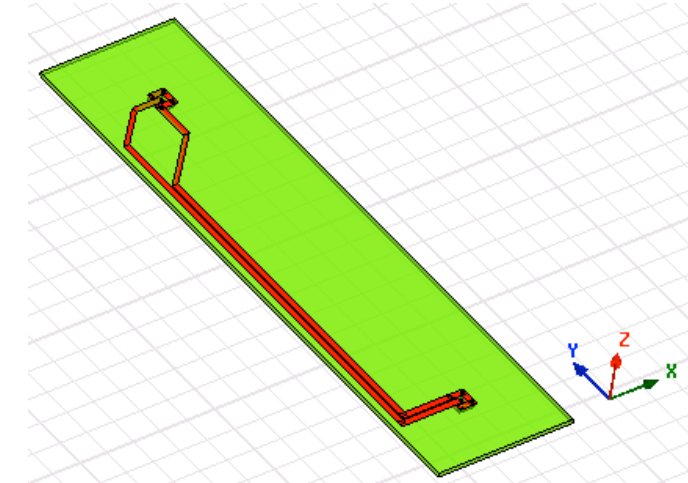

Figure 6: 3-D design of the planar microstrip structure simulated with HFSS.
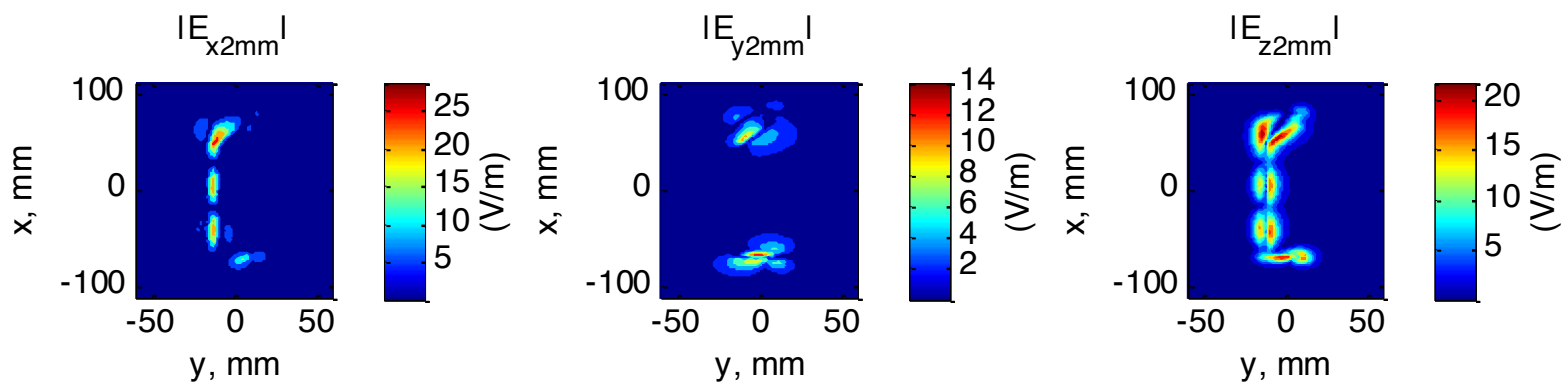

Figure 7: Maps of E-field at $\mathrm{z}=2 \mathrm{~mm}$.
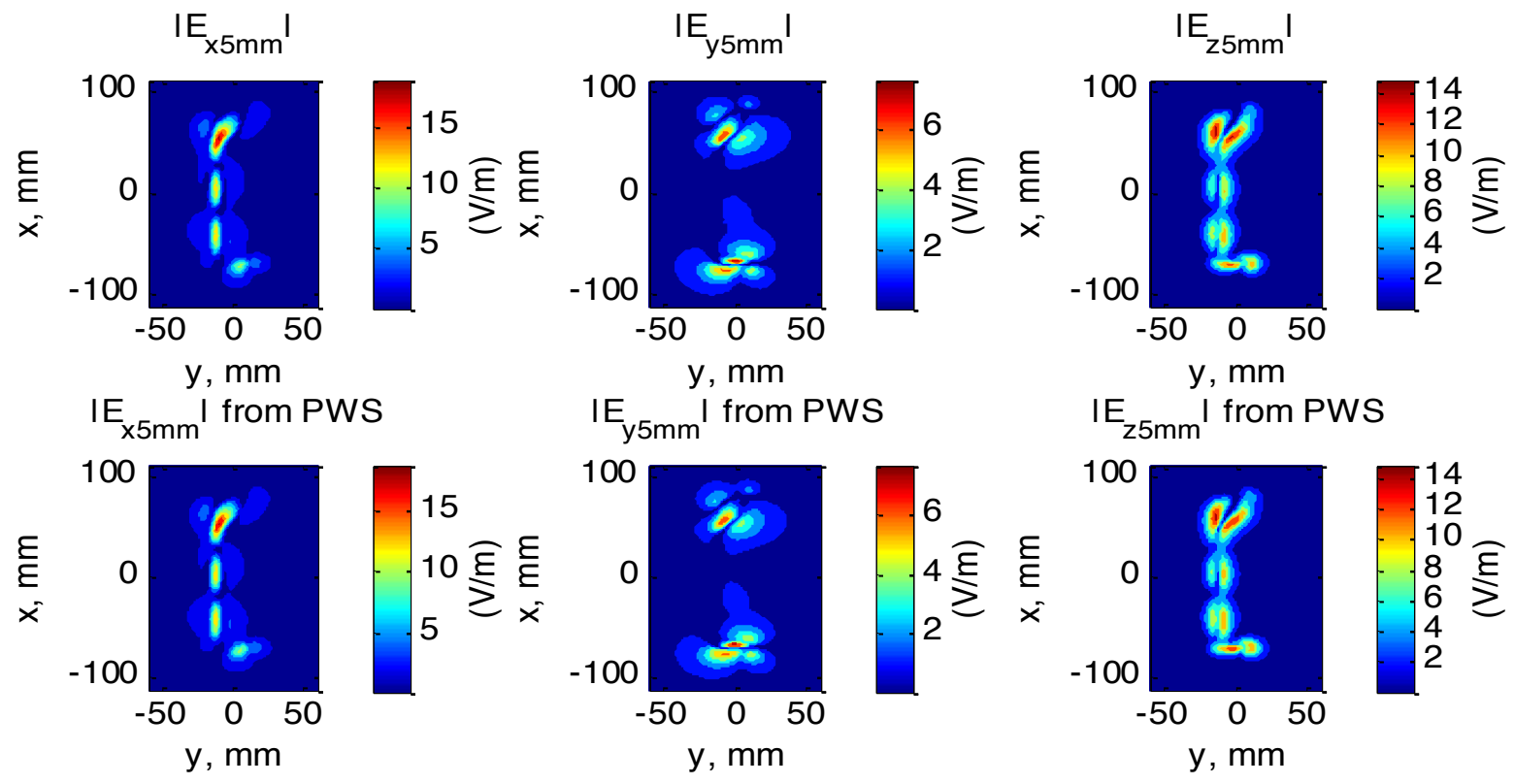

$I E_{z 5 \mathrm{~mm}}$ I from PWS

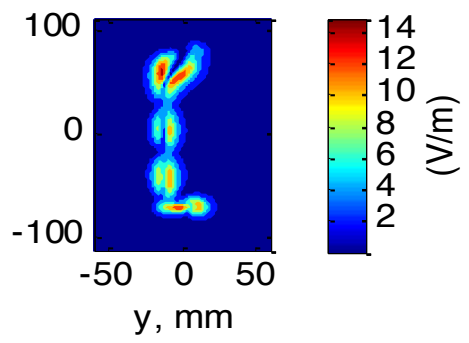

(a) 

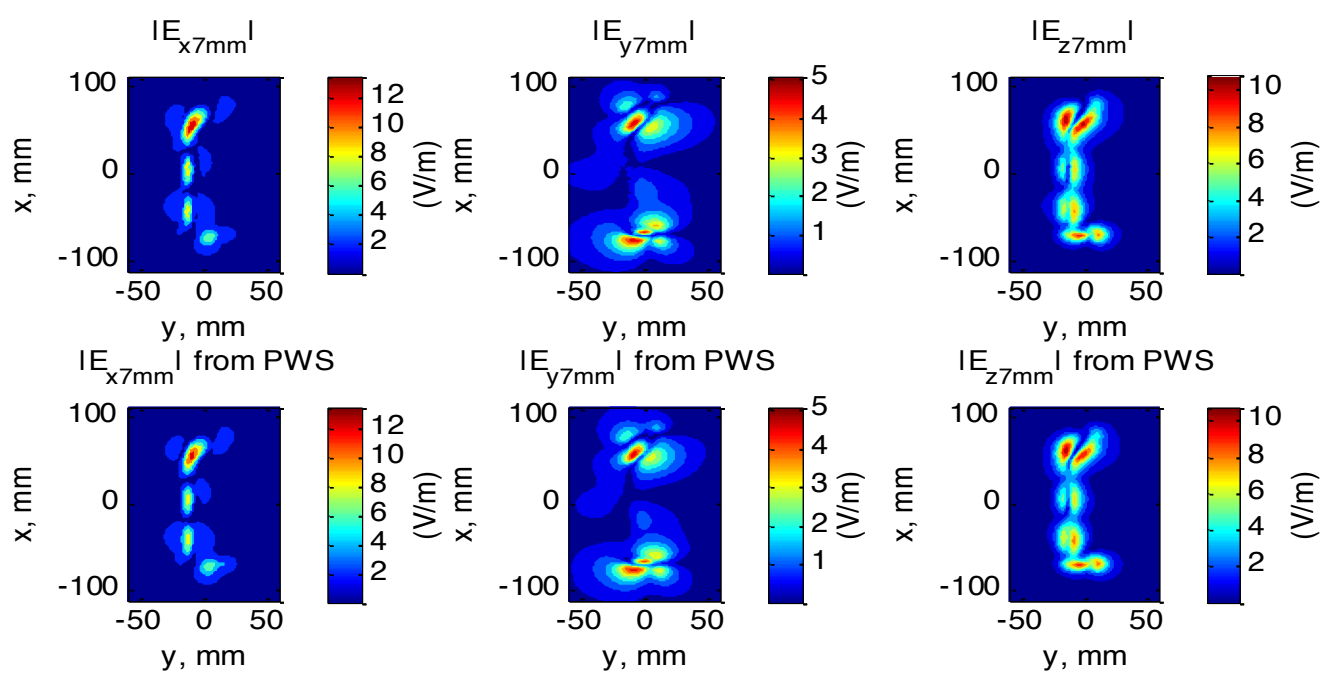

(b)

Figure 8: Comparisons of the E-field maps computed directly from the analytical defintion and from the PWS method proposed at (a) $z=5 \mathrm{~mm}$ and (b) $z=7 \mathrm{~mm}$.
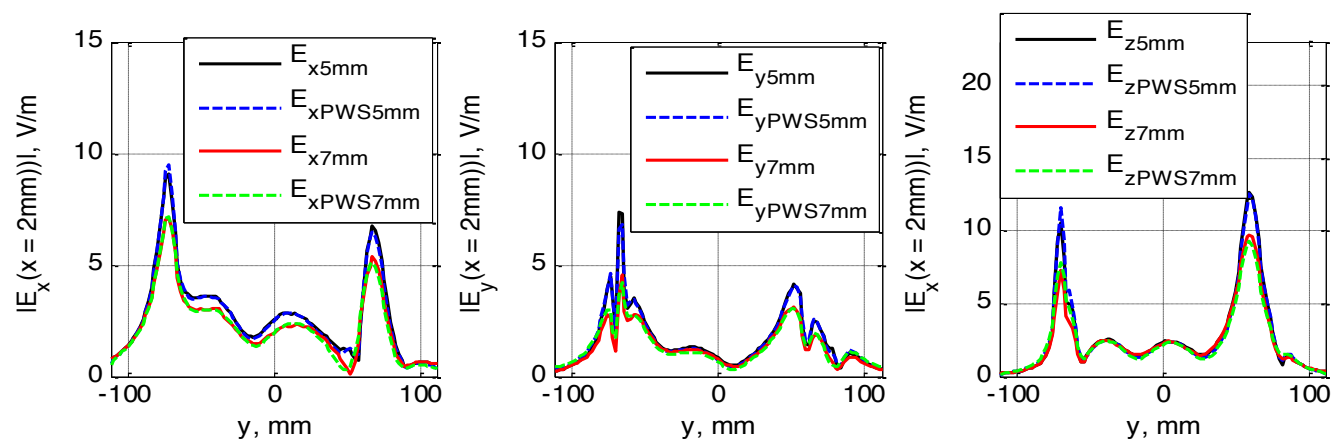

Figure 9: Comparisons of the E-field profiles computed directly from the analytical defintion and from the PWS method proposed at $z=5 \mathrm{~mm}$ and $z=7 \mathrm{~mm}$.

\subsubsection{Validation with experimental results}

The PWS NF/NF method proposed was also verified with measured E-field data radiated by the Wilkinson power divider with the top view presented in Figure 10.

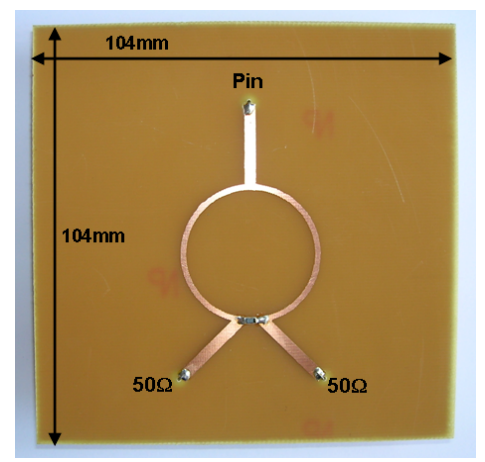

Figure 10: Photograph of the device under test: planar Wilkinson power divider.

This device was printed on the FR4-epoxy substrate having relativity permittivity 4.4 , thickness $1.6 \mathrm{~mm}$ and etched $\mathrm{Cu}-$ metal thickness $35 \mu \mathrm{m}$. It operates at $1 \mathrm{GHz}$. The measured Efield component amplitudes which were scanned in the horizontal plane placed at $z=2 \mathrm{~mm}$ are depicted in Figure 11 . We point out that the measurement plane considered is with dimensions $L_{x}=40 \mathrm{~mm}$ and $L_{y}=62 \mathrm{~mm}$ and the 2D planar space resolutions $\Delta x=1 \mathrm{~mm}$ and $\Delta y=2 \mathrm{~mm}$.

Similar to the previous cases, by considering the E-field maps scanned at the height $\mathrm{z}=2 \mathrm{~mm}$ above the metallic plane of the structure, we deduced the E-field maps in the plane placed at the height $z=5 \mathrm{~mm}$ with the PWS method under study. Therefore, we realize the maps displayed in Figure 12.

As we can see, once again, very good correlations between the behaviours of the E-field components are observed. In addition, the results from the PWS method are visibly cleaner than those from the measurements. It is interesting to note that compared to the exiting commercial tools, we gian here in terms of simplicity and also the computation time durations. The method is particularly helpful for the reduction of the measurement complexity. 


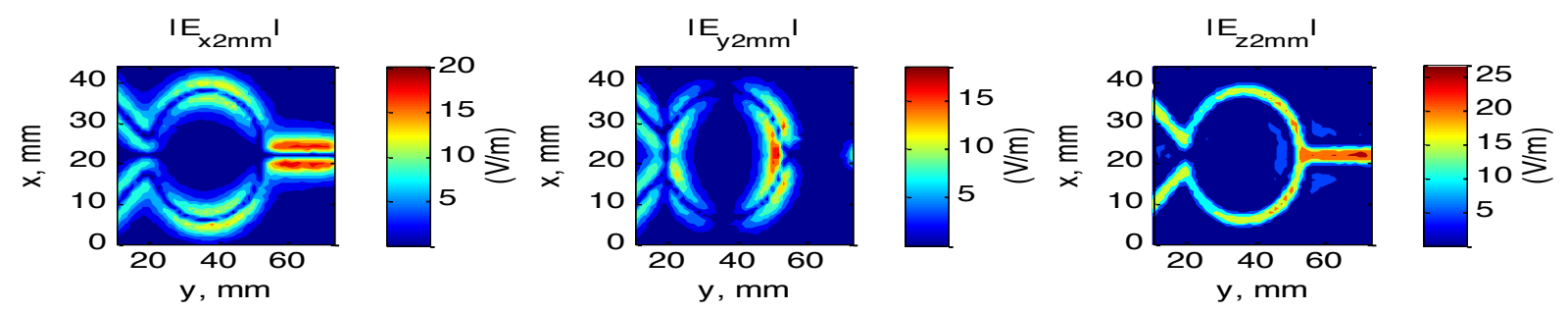

Figure 11: E-field map scanned at $z=2$ above the structure.
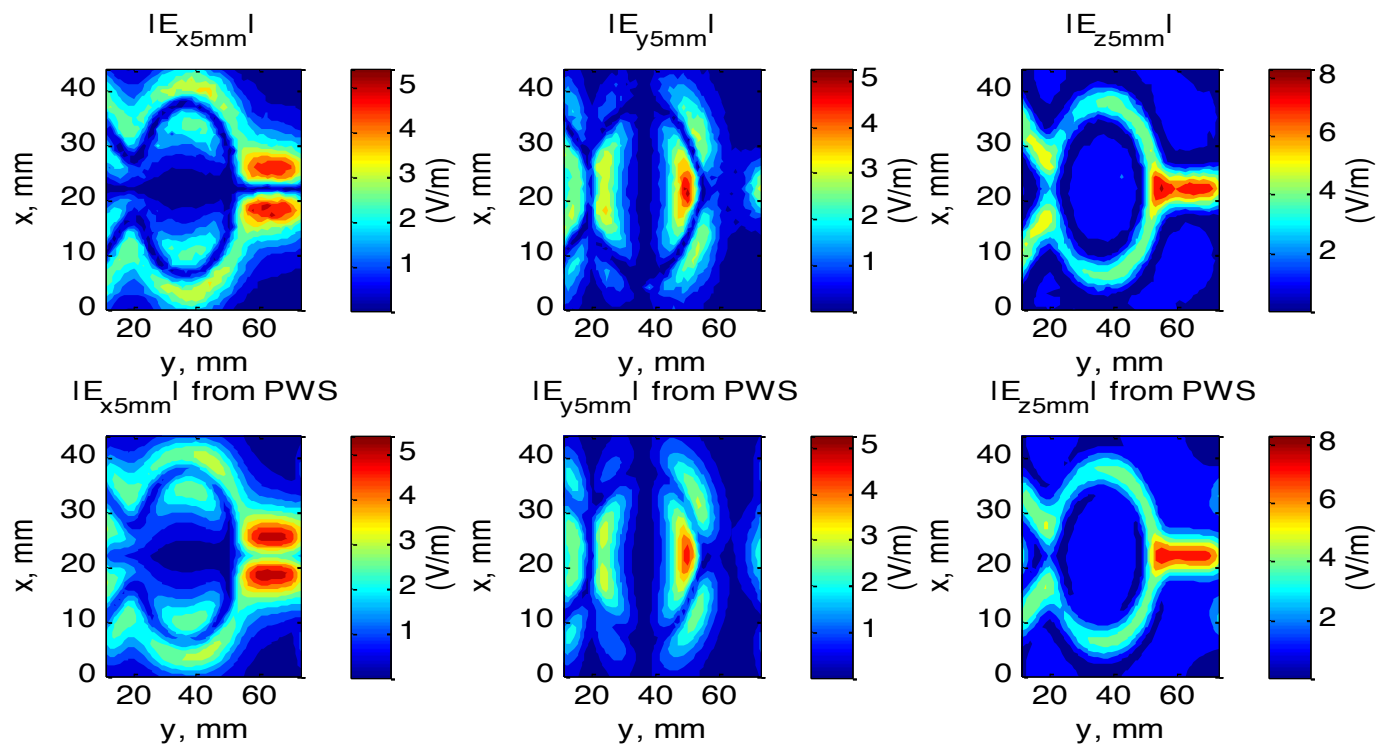

Figure 12: Comparison between the measured E-field maps scanned at $\mathrm{z}=5 \mathrm{~mm}$ and those calculated from the PWS method proposed.

\subsection{Time-domain results}

In this subsection, we considered the EM NF field emitted by an arbitrary shape microstrip device. We point out that the computed data are obtained from the simulations performed with the standard commercial 3D simulation solver CST Microwave Studio and the Matlab program.

\subsubsection{Description of the device under test}

First, the microstrip circular resonator displayed in Figure 13 is designed as device under test (DUT) in order to verify the feasibility of the method under study. The resonator is based on an Alumina substrate with relative permittivity $\varepsilon_{r}=10$.

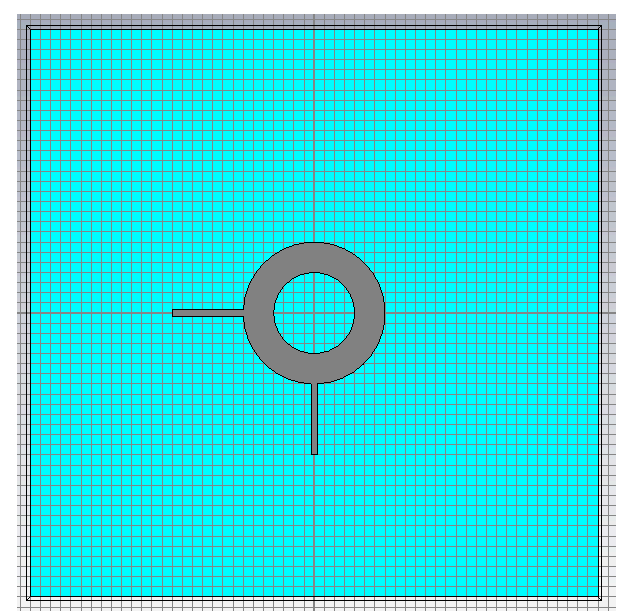

Figure 13: Overview of the microstrip circular resonator.

This circular resonator is fed by the via port with the transient current presented in Figure 14. This excitation $i(t)$ is assumed as a Gaussian signal modulated $1.25 \mathrm{GHz}$ sine carrier. 

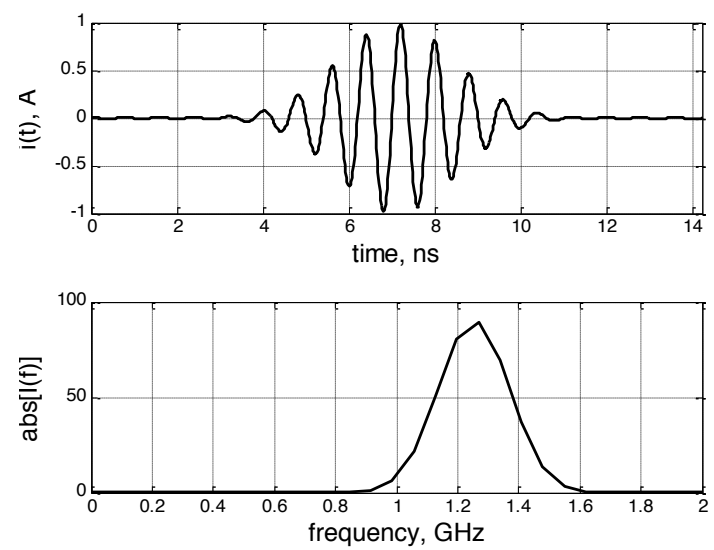

Figure 14: Transient plot of the considered excitation current $i(t)$ and the frequency spectrum $I(f)$.

To validate the method proposed in this article, comparisons of different results were made between the CST Microwave simulations and the computation method proposed.

\subsubsection{Validation by full wave simulations with CST}

The comparisons of different EM field components are illustrated by the cartographies mapped in Figures 15, 16, $17,18,19$ and 20. Furthermore, the profiles of the each EM field components are also plotted in Figures 21 and 22.

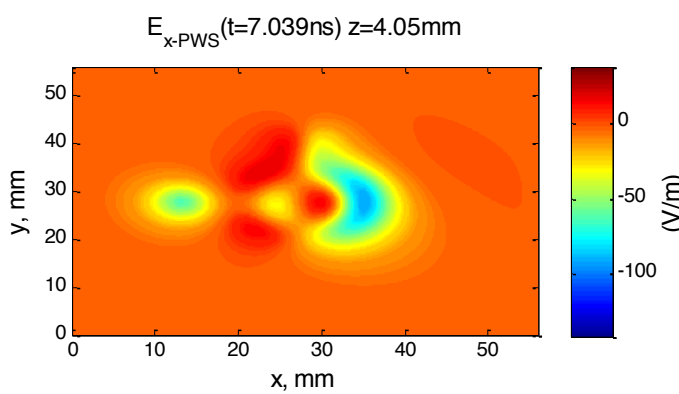

$E_{x-C S T}(t=7.039 n s) z=4.05 \mathrm{~mm}$

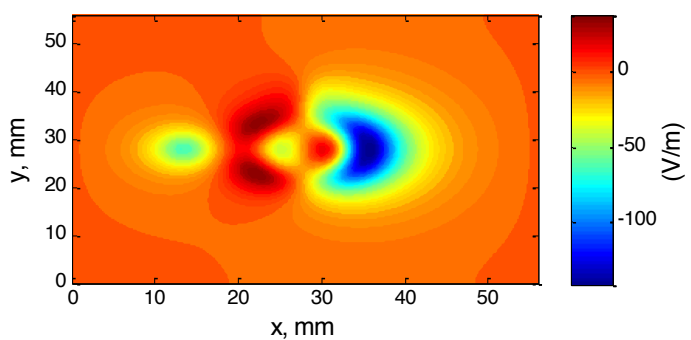

Figure 15: Comparison of $E_{x}$ at $z=4.05 \mathrm{~mm}$ obtained by CST simulation and the proposed computation method.

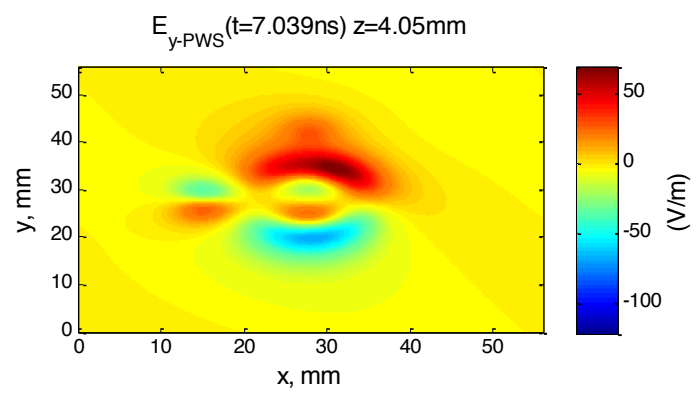

$E_{y-C S T}(t=7.039 n s) z=4.05 \mathrm{~mm}$

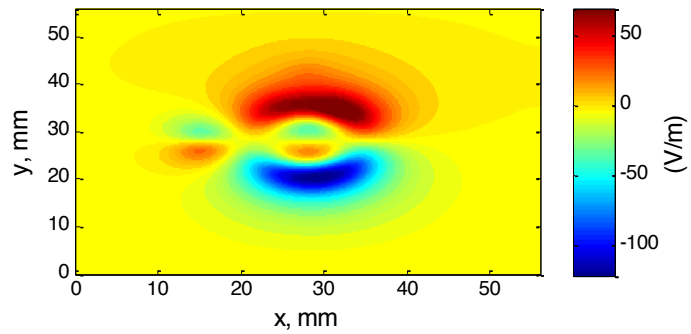

Figure 16: Comparison of $E_{y}$ at $z=4.05 \mathrm{~mm}$ obtained by CST simulation and the proposed computation method.

$E_{z-P W S}(t=7.039 \mathrm{~ns}) \mathrm{z}=4.05 \mathrm{~mm}$

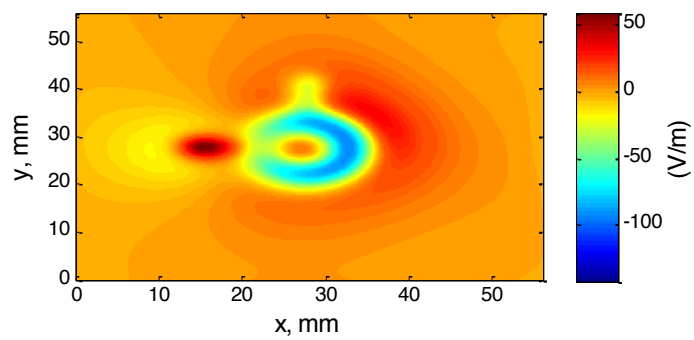

$E_{z-C S T}(t=7.039 n s) z=4.05 \mathrm{~mm}$

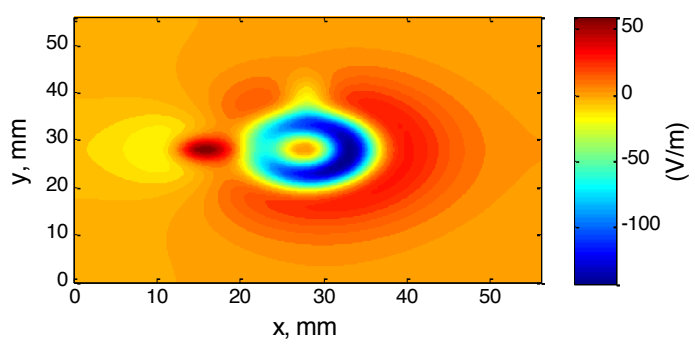

Figure 17: Comparison of $E_{z}$ at $z=4.05 \mathrm{~mm}$ obtained by CST simulation and the proposed computation method. 


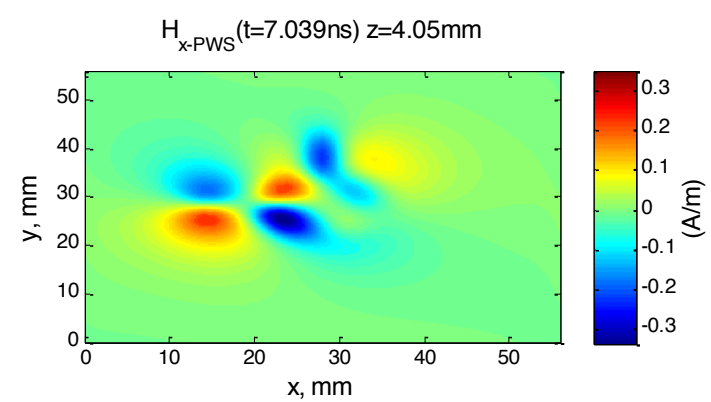

$\mathrm{H}_{\mathrm{x}-\mathrm{CST}}(\mathrm{t}=7.039 \mathrm{~ns}) \mathrm{z}=4.05 \mathrm{~mm}$

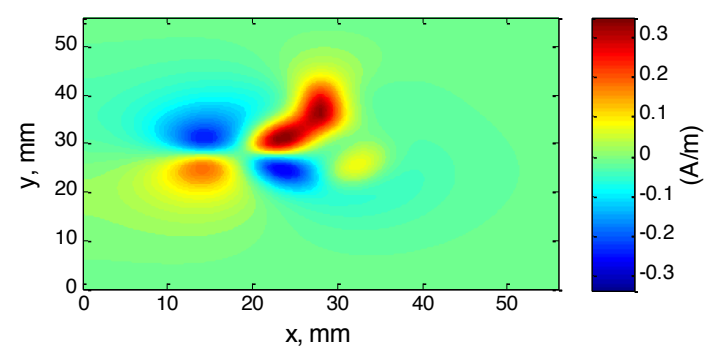

Figure 18: Comparison of $H_{x}$ at $z=4.05 \mathrm{~mm}$ obtained by CST simulation and the proposed computation method.

$H_{y-P W s}(t=7.039 n s) z=4.05 \mathrm{~mm}$

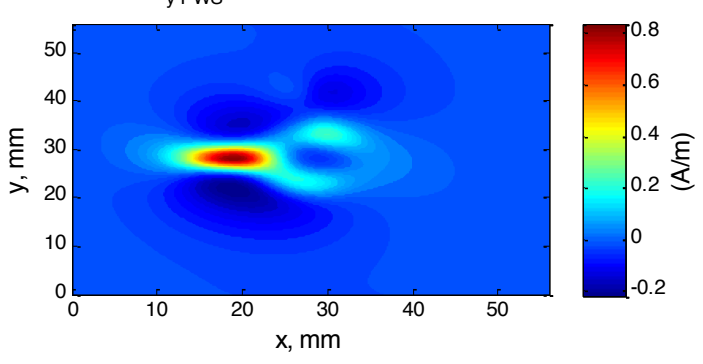

$\mathrm{H}_{\mathrm{y}-\mathrm{CST}}(\mathrm{t}=7.039 \mathrm{~ns}) \mathrm{z}=4.05 \mathrm{~mm}$

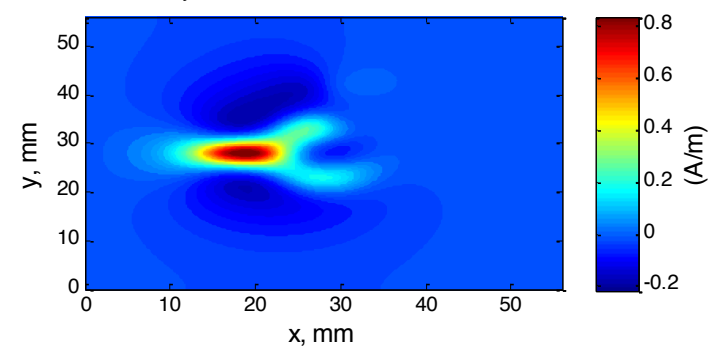

Figure 19: Comparison of $H_{y}$ at $z=4.05 \mathrm{~mm}$ obtained by CST simulation and the proposed computation method.

As a matter of fact, one can see the quite good agreement can be found between the cartographies of the different time-domain electric or magnetic field components achieved by the CST simulation and our proposed PWS method.

However, some difference can be figured out, mainly caused by the numerical errors during the calculating process and also the imperfection of the considered full wave simulations. As further study, profile comparisons along a line in the plane are displayed by figures 21 and 22 .

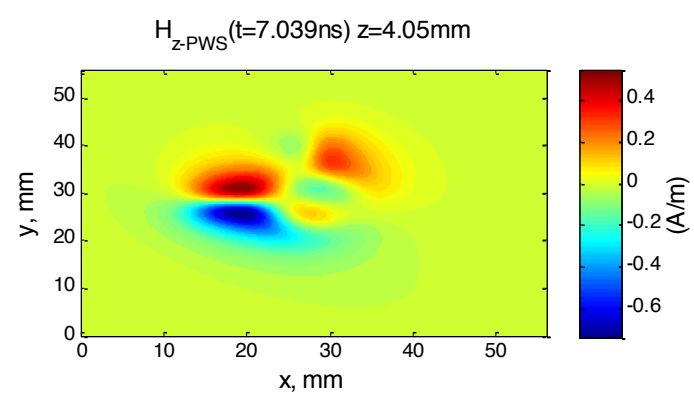

$\mathrm{H}_{\mathrm{z}-\mathrm{CST}}(\mathrm{t}=7.039 \mathrm{~ns}) \mathrm{z}=4.05 \mathrm{~mm}$

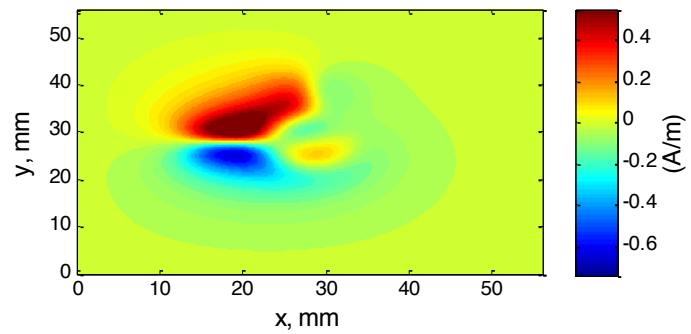

Figure 20: Comparison of $H_{z}$ at $z=4.05 \mathrm{~mm}$ obtained by CST simulation and the proposed computation method.

Profile comparison of $E_{x} @ x=15.3 m m$

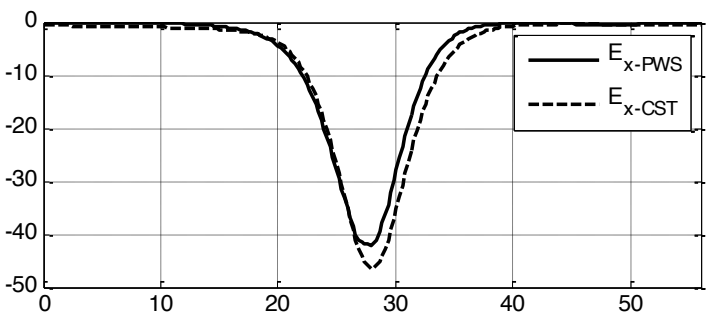

Profile comparison of $E_{y} @ x=15.3 m m$

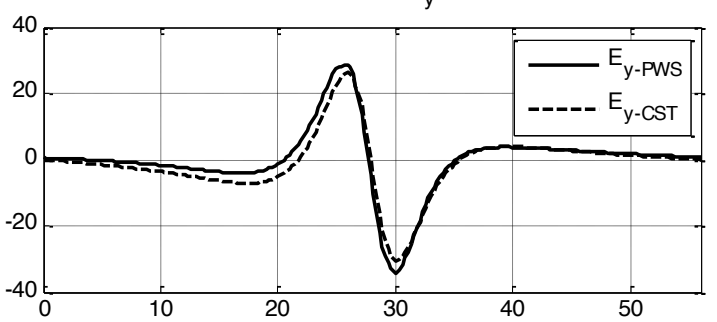

Profile comparison of $E_{z} @ x=15.3 m m$

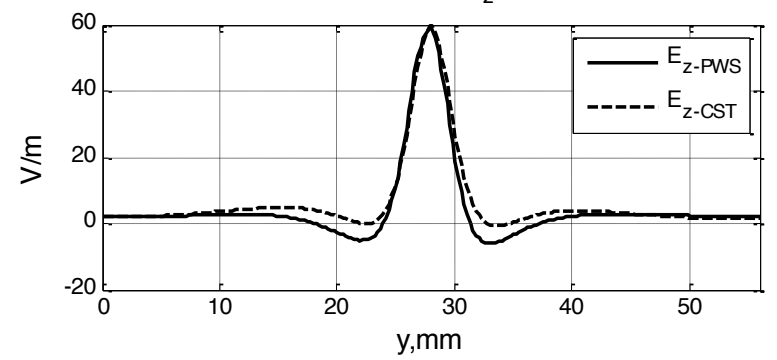

Figure 21: Comparisons of the electric field components profiles obtained from the proposed PWS computation method and the CST simulation, detected in the vertical cutplan $x=15.3 \mathrm{~mm}$. 

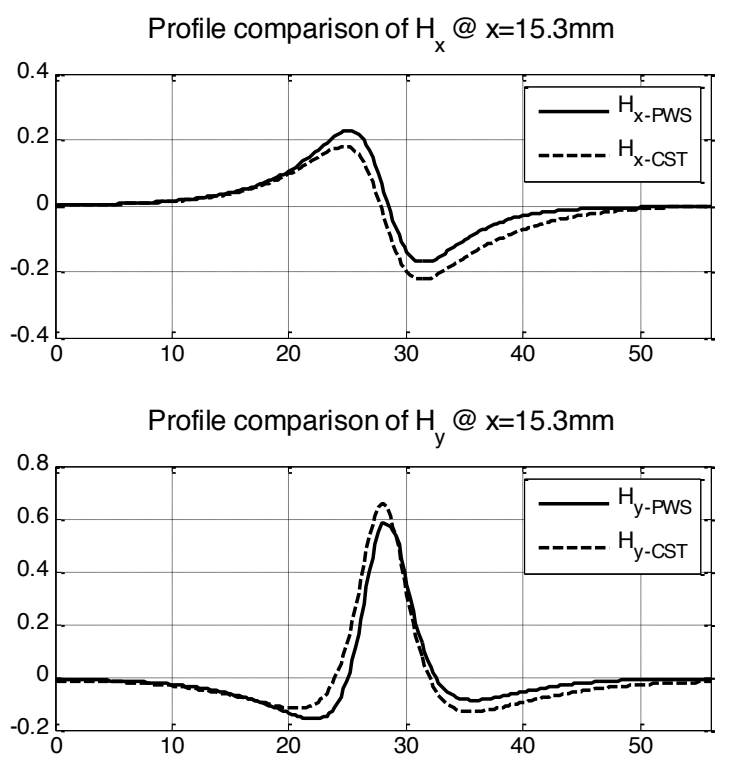

Profile comparison of $\mathrm{H}_{\mathrm{z}} @ \mathrm{x}=15.3 \mathrm{~mm}$

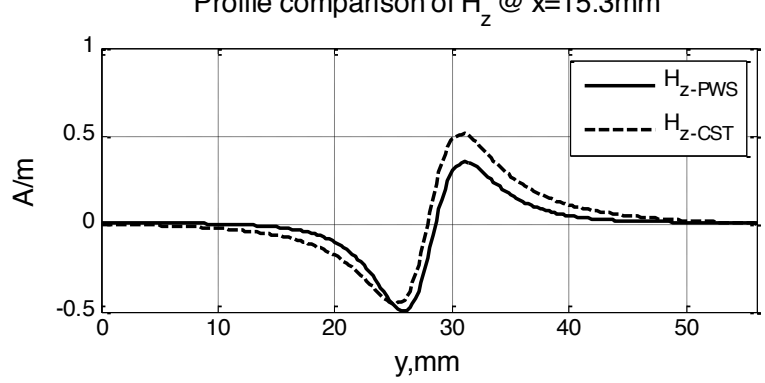

Figure 22: Comparisons of the magnetic field components profiles obtained from the proposed PWS computation method and the CST simulation, detected in the vertical cutplan $x=15.3 \mathrm{~mm}$.

Once again, quite good correlations between the results from the method proposed and CST simulations are found. Compared to the computation tools and the methods indicated in [77-86], it is noteworthy that the computation methods established in this paper, we have benefits in terms of the simplicity and the execution time of the algorithm. Furthermore, the method presented here does not depend on the complexity of the structure under consideration.

\section{Transient NF modelling for microwave circuit radiating emissions}

This section is devoted to the development of a time-domain modelling method of electromagnetic (EM) near-field (NF) radiated by electronic devices excited by transient pulse signals as introduced in [69]. This time-dependent model is based on the ultra wide band (UWB) frequency model of EM NF maps using a set of elementary dipoles. The number of EM NF maps can be reduced by an innovative algorithm in order to establish simply the dipole model. Then, the transient model can be realized by considering the convolution between the transient excitation signals and the dipole-array model. The method proposed was validated by a standard 3D EM tool with a planar microstrip device excited by microwave signal modulating $1.25 \mathrm{GHz}$ carrier with $0.5 \mathrm{GHz}$ bandwidth. As expected, good correlation is found between results from simulation and the investigated modelling method.

\subsection{Broadband radiating model of EM NF emitted by microwave devices}

The time dependent model presented in this paper is determined from the given EM NF data combined with the time-frequency computational technique introduced in [74]. Before the exploration of the time-domain modelling method, let us first, review the process of establishment of the dipole model in frequency-domain with the EM field data as reported in [69].

\subsubsection{Review on the EM NF modelling method by using a set of elementary dipole [69]}

First of all, let us consider the EM field data is in XY plane with $n_{x} \times n_{y}$ points at the height $z_{0}$ above the radiating source. The model is based on a set of electric or magnetic dipoles placed on an XY plane considered as the upper surface of the under-test radiating device. This single-frequency monochromatic NF model is determined by [34]:

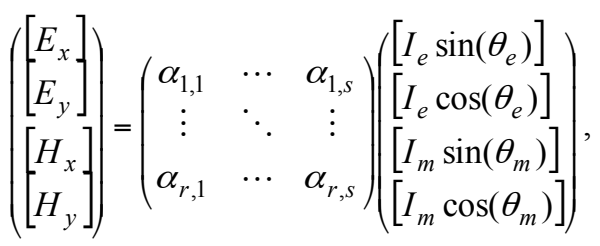

where $\left[\alpha_{r, s}\right]$ is a matrix whose elements depend on the frequency and the centres and lengths of the dipole. The unknown variables of the model are the orientations $\theta_{e}$ and the currents $I_{e}$ for electronic dipoles and the orientations $\theta_{m}$ and the currents $I_{m}$ for magnetic dipoles. To determine the unknown parameters of the model, the cartographies of the NF horizontal components $E_{x}, E_{y}, H_{x}$ and $H_{y}$ at a certain height above the radiating device are required.

The first step for generating the model is to find out the orientations for each electric or magnetic dipole by using the inverse matrixes expression below:

$$
\left(\begin{array}{ccc}
\alpha_{1,1} & \cdots & \alpha_{1, s} \\
\vdots & \ddots & \vdots \\
\alpha_{r, 1} & \cdots & \alpha_{r, s}
\end{array}\right)^{-1}\left(\left[\begin{array}{l}
\left.E_{x}\right] \\
\left.E_{y}\right] \\
{\left[H_{x}\right.} \\
H_{y}
\end{array}\right]\right)=\left(\begin{array}{l}
{[A]} \\
{[B]} \\
{[C]} \\
{[D]}
\end{array}\right)=\left(\begin{array}{l}
{\left[I_{e} \sin \left(\theta_{e}\right)\right]} \\
{\left[I_{e} \cos \left(\theta_{e}\right)\right]} \\
{\left[I_{m} \sin \left(\theta_{m}\right)\right]} \\
{\left[I_{m} \cos \left(\theta_{m}\right)\right]}
\end{array}\right),(8)
$$

The orientations of each dipole are given by:

$$
\begin{gathered}
{\left[\theta_{e}\right]=\arctan \left(\begin{array}{l}
{[A]} \\
{[B]}
\end{array}\right),} \\
{\left[\theta_{m}\right]=\arctan \left(\begin{array}{l}
{[C]} \\
{[D]}
\end{array}\right),}
\end{gathered}
$$


Then, the currents exciting each dipole can be extracted from the following formula:

$$
\begin{aligned}
& {\left[I_{e}\right]=\left[\begin{array}{l}
\sin \left(\theta_{e}\right) \\
\cos \left(\theta_{e}\right)
\end{array}\right]^{-1}\left[\begin{array}{l}
A \\
B
\end{array}\right],} \\
& {\left[I_{m}\right]=\left[\begin{array}{l}
\sin \left(\theta_{m}\right) \\
\cos \left(\theta_{m}\right)
\end{array}\right]^{-1}\left[\begin{array}{l}
C \\
D
\end{array}\right],}
\end{aligned}
$$

After all, the dipole model can be built finally by considering the matrix $\left[\alpha_{r, s}\right]$. It is interesting to note that only the horizontal NF components are sufficient for creating the model in $3 \mathrm{D}$ because the vertical components can be generated automatically by the set of dipoles.

\subsubsection{Reduction of the field map data number for the model reduction}

As expected, more given field maps can improve the model accurate, but also slow down the calculation process. For this reason, by considering the relative error between the nearby maps, one can reduce the number of given field maps in order to accelerate the modelling process.

We suppose that there are $n_{f}$ maps given in the band frequency delimited from $f_{\min }=f_{1}$ to $f_{\max }=f_{n f}$. Accordingly, the frequency step is $\Delta f=\left(f_{\max }-f_{\min }\right) / n_{f}$. Then, the relative error between the nearby field maps $n_{k 1}$ and $n_{k 2}$ is determined by the following expression.

$$
\varepsilon_{n_{k 2}}=\sum_{i} \frac{\left|E, H_{n k 2}\left(M_{i}\right)-E, H_{n k 1}\left(M_{i}\right)\right|^{2}}{\sum_{j} \mid E, H_{n k 1}\left(\left.M_{j}\right|^{2}\right.},
$$

We can reduce the number of field maps from $n_{f}$ to $r n_{f}$ by assuming the nearby field maps as identical which present the relative error smaller than 5\%. Therefore, a reduced model can be realized. With the inverse process, we can generate the total frequency data from $f_{1}$ to $f_{n f}$ as given initially. By considering the convolution with the transient excitation signal, this frequency-dependent model can be extended to the time-domain.

\subsubsection{Methodology of the proposed time-domain modelling method}

Let us denote $i(t)$ the transient excitation signal discretized from the starting time $t_{\min }$ to the stop time $t_{\max }$ with time step equal to $\Delta t$. In this case, the number $n$ of time-domain sample data is equal to:

$$
n=\operatorname{int}\left[\left(t_{\max }-t_{\min }\right) / \Delta t\right]
$$

Accordingly, the equivalent frequency-dependent spectrum of $i(t)$ can be determined via the fast Fourier transform $(f f t)$ which allows to provide the complex current harmonic $I(f)=$ $f f t[i(t)]$ in function of the sampled frequency [68]. The frequency-dependent of the discrete signal spectrum complex coefficients is denoted $\underline{c}_{k}=\underline{I}(k \cdot \Delta f)$ at each frequency $f_{k}=k \cdot \Delta f$ for $k=\{1 \ldots n\}$ having step-frequency given by:

$$
\Delta f=\frac{1}{t_{\max }-t_{\min }},
$$

By convoluting the current harmonic $I(f)$ and the model built in previous section, and with the inverse Fourier transform (ifft), one can carry out the dipole field model in timedomain. The work flow of the modelling method proposed is summarized mainly in five steps illustrated by Figure 23 .

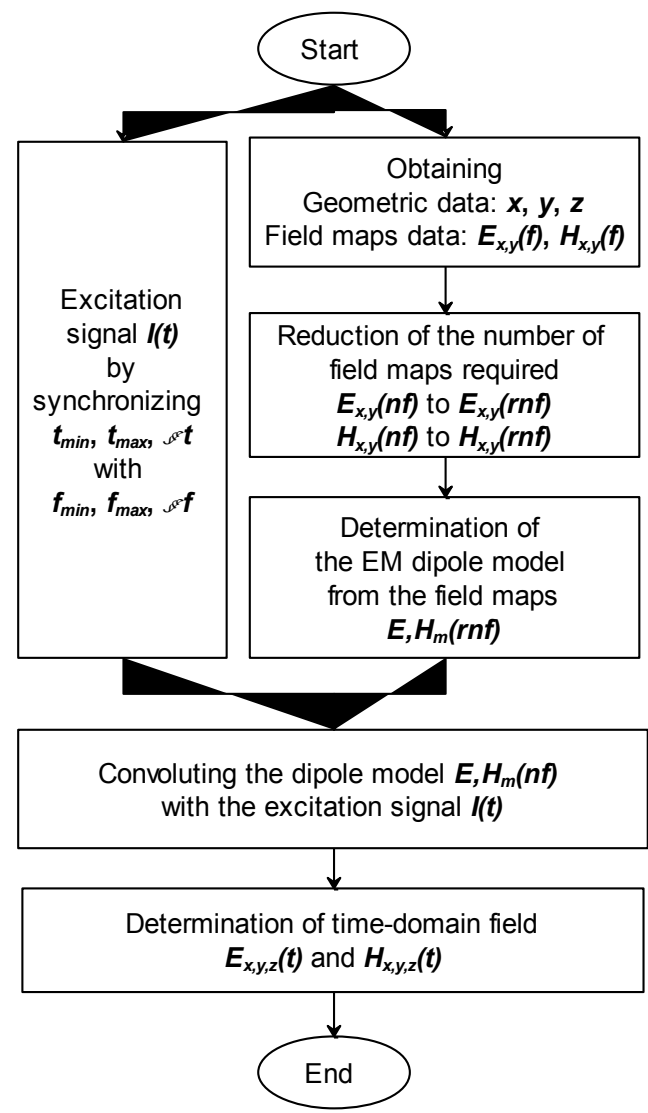

Figure 23: Work flow summarizing the time-frequency modelling method proposed.

\subsection{Validation results}

To demonstrate the effectiveness of the method proposed, a planar microstrip device shown in Figure 24 was designed and simulated by HFSS in the frequency-domain and by CST Microwave Studio in the time-domain. The structure under consideration is the butterfly planar microstrip filter presented in Figure 24. It is printed on the FR4-substrate. The frequency-dependent field maps were sample with 51 frequency points from $1 \mathrm{GHz}$ to $1.5 \mathrm{GHz}$ with the help of HFSS. 


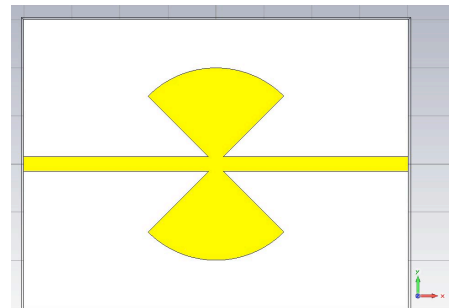

Figure 24: Device under study: planar microstrip filter.

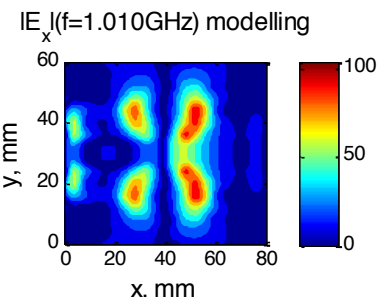

$\mathrm{x}, \mathrm{mm}$

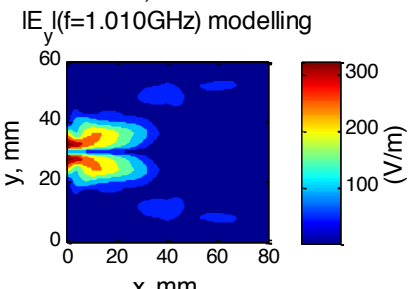

$\mathrm{IE}_{\mathrm{z}} \mathrm{I}(\mathrm{f}=1.010 \mathrm{GHz})$ modelling

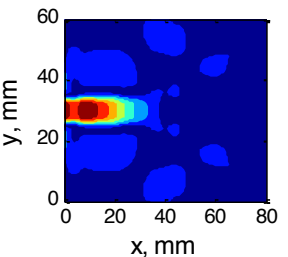

$\mathrm{x}, \mathrm{mm}$

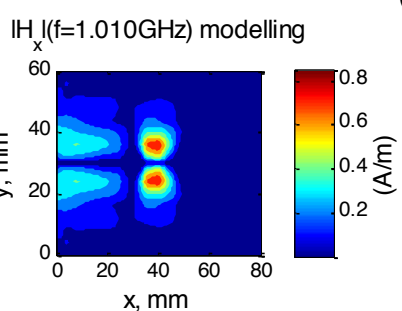

$\| \mathrm{H}_{\mathrm{y}} \mid(\mathrm{f}=1.010 \mathrm{GHz})$ modelling

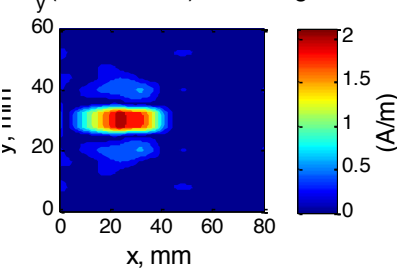

$\mathrm{IH}_{z} \mid(\mathrm{f}=1.010 \mathrm{GHz})$ modelling

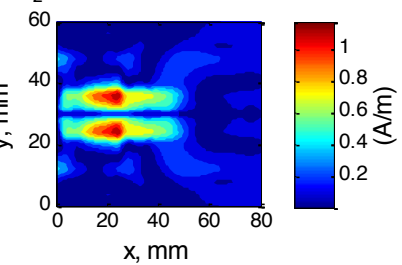

(b)

(a)
$I_{x} \mid(f=1.010 G H z)$ from HFSS

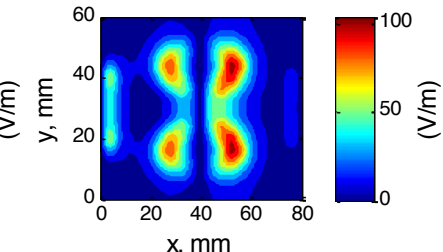

$\mathrm{IE}_{y} \mid(\mathrm{f}=1.010 \mathrm{GHz})$ from HFSS

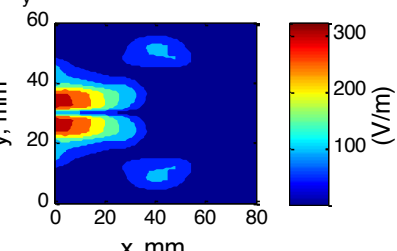

$\mathrm{IE}_{\mathrm{z}} \mid(\mathrm{f}=1.010 \mathrm{GHz})$ from HFSS
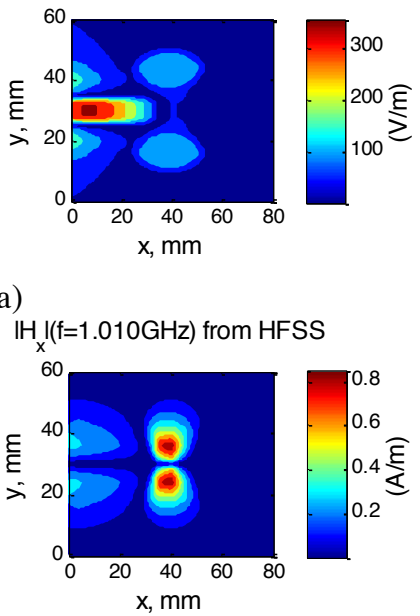

$\mathrm{HH}_{\mathrm{y}} \mathrm{l}(\mathrm{f}=1.010 \mathrm{GHz})$ from HFSS

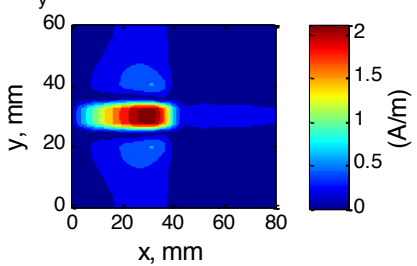

$\mathrm{IH}_{\mathrm{z}} \mid(\mathrm{f}=1.010 \mathrm{GHz})$ from HFSS

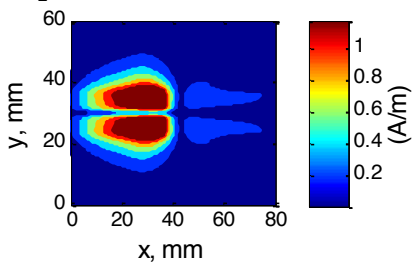

Figure 25: Comparisons of E-field (a) and H-field (b) components obtained by the dipoles model and HFSS in the frequency-domain.

With the reduction process introduced in paragraph 4.1.2, the number of field maps was reduced to $n_{r f}=13$ instead of $n_{f}=51$ frequency samples. Obviously, this allows accelerating the computation process. As described in the routine process, the dipoles model is extracted from the frequency-dependent field maps, so the first validation is carried out in the frequency-domain. To verify the accuracy of dipole-array model, we compare the E- and $\mathrm{H}$-field obtained by the proposed modelling method and HFSS simulation in the frequency-domain. The comparison results are shown in Figure 25. A slight similar correlation can be observed in this figure. However, undeniable relative difference can be noticed. To quantify the level of this numerical difference between these two field maps, errors analysis technique as reported in [87] was considered. According to this method, we assess relative errors presented in Table 1.

\begin{tabular}{|c|c|c|c|c|c|c|}
\cline { 2 - 7 } \multicolumn{1}{c|}{} & $E_{x}$ & $E_{y}$ & $E_{z}$ & $H_{x}$ & $H_{y}$ & $H_{z}$ \\
\hline $\begin{array}{c}\text { Error } \\
\%\end{array}$ & 0.27 & 1.28 & 1.99 & 0.92 & 1.54 & 4.33 \\
\hline
\end{tabular}

Table 1: Relative errors of $\mathrm{E}$ - and $\mathrm{H}$-field maps obtained in the frequency-domain.

As expected, very low relative errors can be found for the horizontal field components. Otherwise, we have higher error level for the vertical field components which still remain as a problem for NF characterization. To improve these vertical components, one can apply the NF extraction method proposed by authors in [63-66]. Furthermore, by considering the transient excitation which is a Gaussian signal modulated 1.25-GHz-sine carrier plotted in Figure 26, we compare the EM NF maps obtained by the proposed method and CST simulations in the time-domain.
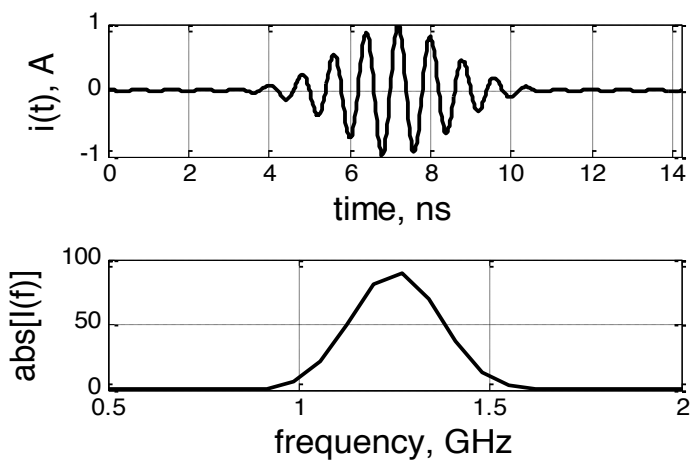

Figure 26: Transient current excitation signal (in top) and the corresponding spectrum (in bottom).

Figures 27 displays the comparison results obtained with those from CST MWS and from the dipole-array model at the arbitrary instant time $t=7.611 \mathrm{~ns}$ scanned at $z=6 \mathrm{~mm}$ above the DUT. 

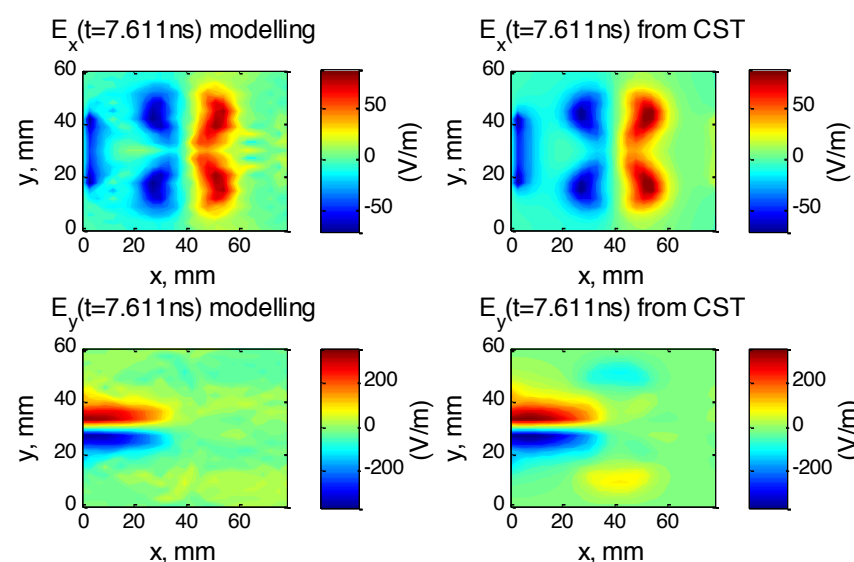

$E_{y}(t=7.611 n s)$ from CST

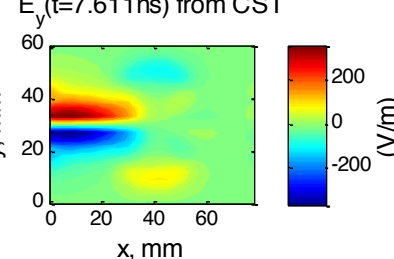

$\mathrm{E}_{\mathrm{z}}(\mathrm{t}=7.611 \mathrm{~ns})$ modelling
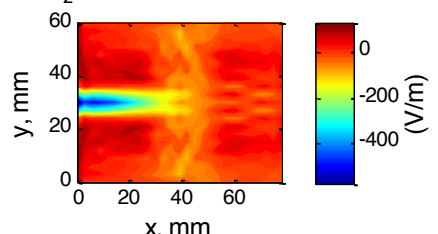

$E_{z}(t=7.611 n s)$ from CST

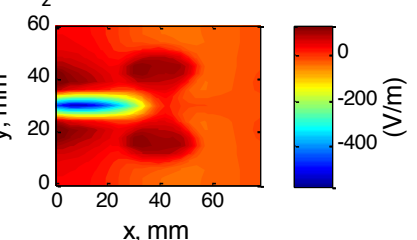

(a)
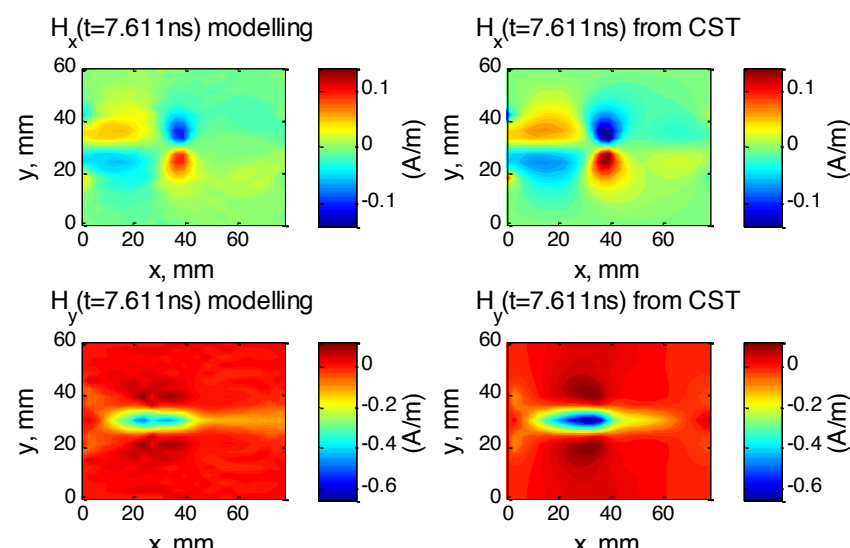

$H_{y}(t=7.611 n s)$ from CST

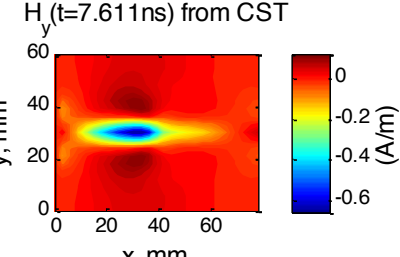

$\mathrm{H}_{\mathrm{z}}(\mathrm{t}=7.611 \mathrm{~ns})$ modelling

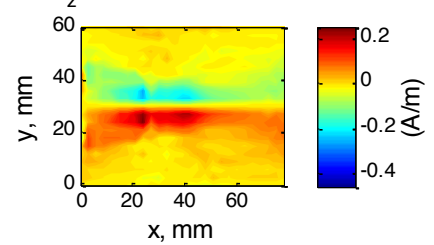

$\mathrm{H}_{\mathrm{z}}(\mathrm{t}=7.611 \mathrm{~ns})$ from CST

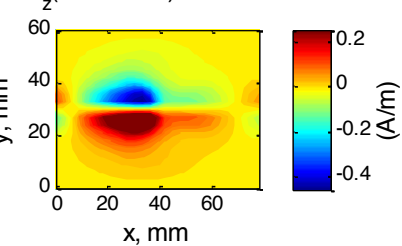

(b)

Figure 27: Comparison of the E-field (a) and H-field (b) components obtained from the investigated modeling method and CST MWS in the time-domain.

As shown in Figures 27, good agreement between the simulations and the time-frequency modelling method proposed was found. We emphasize than the relative errors can be neglected when the NF field intensity is very low. In the same way as the previous case, we obtain the relative errors between the time-domain field maps, shown in Table 2.

\begin{tabular}{|c|c|c|c|c|c|c|}
\cline { 2 - 7 } \multicolumn{1}{c|}{} & $E_{x}$ & $E_{y}$ & $E_{z}$ & $H_{x}$ & $H_{y}$ & $H_{z}$ \\
\hline $\begin{array}{c}\text { Error } \\
\%\end{array}$ & 0.23 & 0.97 & 3.92 & 1.12 & 1.69 & 4.48 \\
\hline
\end{tabular}

Table 2: Relative errors of E- and H-field maps obtained in the time-domain.

Once again, one gets more significant errors for the vertical field components. Otherwise, the accuracy of the dipoles model is strongly dependent on the spatial resolution of the field maps required. Accordingly, there is tradeoff for higher modelling accuracy which requests higher spatial resolution and consequently huge physical computation memory. We point out that a PC having 3.5 Gbytes RAM memory was employed to perform the calculations. Then, we also reduce the space resolution as $16 \times 21$ points in the $2 \mathrm{D}$ plane with a surface of $60 \times 80 \mathrm{~mm}^{2}$.

\section{Conclusions}

Two different computation methods of the time-frequency EM NF processing are successfully presented in this paper. The first method proposed is a NF/NF transform based on the PWS method. This method is dedicated to deduce the EM NF maps from the given EM NF maps which can be obtained by simulations or modelling or measurements. The theoretical approach of this NF/NF transform is illustrated by the processing algorithm. Then, the validation results were performed by considering different ways (analytical, numerical and measurement) in both the frequency- and the time-domain. As results, good correlations were achieved between the different results obtained. Then, errors analysis is also made and allowing to state that the global relative errors of the whole field maps obtained are lower than $5 \%$.

The second part of this paper is focused on the timefrequency EM NF emission modelling. The proposed NF modelling uses a dipoles array as the equivalent radiating source [29-33]. By combining time- and frequency-domain approaches, an effective way for modelling the time-domain NF radiation is established. The feasibility of the method was once again validated with full wave numerical simulations. As expected, relatively good agreements between the behaviours of field maps were observed with the low relative errors. With this method, one can predict the time-domain radiation of microwave devices excited by any rapid transient signals.

In summary, the approaches introduced in this paper can be particularly useful for the time-domain EM NF prediction and characterization for EMC applications. As the perspective of future works, we envisage to apply these methods for the treatment of EM NF radiations, in order to solve the typical EMI/EMC issues happening in the complex/hybrid systems. 


\section{Acknowledgements}

Acknowledgement is made to European Union (EU) and Upper Normandy region (FRANCE) for the support of this research project "Time-Domain Electromagnetic Characterization and Simulation (TECS)". This project has been selected in the context of the INTERREG IV A France (Channel) - England European cross-border co-operation programme, which is co-financed by the ERDF.

\section{References}

[1] T. Yang, Y. Bayram and J. L. Volakis, "Hybrid Analysis of Electromagnetic Interference Effects on Microwave Active Circuits Within Cavity Enclosures," IEEE Trans. EMC, Vol. 52, No. 3, pp. 745-748, Aug. 2010.

[2] B. Archambeault, C. Brench and S. Connor, "Review of Printed-Circuit-Board Level EMI/EMC Issues and Tools," IEEE Tran. EMC, Vol. 52, No. 2, pp. 455-461, May 2010.

[3] B. Revol, J. Roudet, J. L. Schanen and P. Loizelet, "EMI study of a three phase inverter-fed motor drives," Proc. IEEE IAS Annual Meeting 2004, Vol. 4, pp. 26572664, 3-7 Oct. 2004.

[4] F. de Daran, J. Chollet-Ricard, F. Lafon and O. Maurice, "Prediction of the field radiated at one meter from PCB's and microprocessors from near EM field cartography," Proc. IEEE Int. Symp. EMC, Istanbul, Turkey, pp. 479-482, May 2003.

[5] D. Vye, "EMI by the dashboard light," Microwave Journal, Vol. 54, No. 7, pp. 20-23, Jul. 2011.

[6] K. Aunchaleevarapan, K. Paithoonwatanakij, W. Khanngern and S. Nitta, "Novel method for predicting PCB configurations for near-field and far-field radiated EMI using a neural network," IEICE Tran. Commun., Vol. E86-B, No. 4, pp. 1364-1376, Apr. 2003.

[7] J. J. Laurin, Z. Ouardhiri and J. Colinas, "Near-field imaging of radiated emission sources on printed-circuit boards," Proc. IEEE Int. Symp. EMC, Vol. 1, pp. 368373, Aug. 2001.

[8] P.-A. Barriere, J.-J. Laurin and Y. Goussard, "Mapping of Equivalent Currents on High-Speed Digital Printed Circuit Boards Based on Near-Field Measurements," IEEE Tran. EMC, Vol. 51, No. 3, pp. 649 - 658, Aug. 2009.

[9] T. Ostermann and B. Deutschmann, "TEM-cell and surface scan to identify the electromagnetic emission of integrated circuits," Proc. of 13th ACM Great Lakes Symp. VLSI, Washington, DC, USA, pp. 76-79, 2003.

[10] T. Hubing, "Ensuring the Electromagnetic Compatibility of Safety Critical Automotive Systems," Invited Plenary Speaker at the 2011 APEMC, Jeju, S. Korea, May 2011.

[11] S. Chen, T. W. Nehl, J.-S. Lai, X. Huang, E. Pepa, R. De Doncker and I. Voss, "Towards EMI prediction of a
PM motor drive for automotive applications," Proc. 18th Annual IEEE Applied Power Electronics Conference and Exposition, APEC'03, Orlando, FL, USA, Vol. 1, pp. 14-22, 9-13 Feb. 2003.

[12] M. Wiles, "An overview of automotive EMC testing facilities," Automotive EMC Conference 2003, Milton Keynes, UK, Nov. 6, 2003.

[13] J. Shin, "Automotive EMC standards and testing," Tutorial Workshop Digests on "Introduction to Automotive EMC Testing" at the 2011 APEMC, Jeju, S. Korea, May 2011.

[14]K. Liu, "An update on automotive EMC testing," Microwave Journal, Vol. 54, No. 7, pp. 40-46, Jul. 2011.

[15] C. D. Taylor, R. S. Sattewhite and C. W. Harrison, "The response of a terminated two-wire transmission line excited by a nonuniform electromagnetic field," IEEE Tran. Ant. Prop., Vol. 13, No. 6, pp. 987-989, Nov. 1965.

[16] A. K. Agrawal and H. J. Price, "Transient response of multiconductor transmission lines excited by a non uniform electromagnetic field," IEEE Tran. Ant. Prop., Vol. 18, pp. 432- 435, Jun. 1980.

[17]F. Rachidi, "Formulation of the field to transmission line coupling equations in terms of magnetic excitation field," IEEE Tran. EMC, Vol. 35, no. 3, pp. 404-407, Aug. 1993.

[18] L. Paletta, J. P. Parmantier, F. Issac, P. Dumas and J. C. Alliot, "Susceptibility analysis of wiring in a complex system combining a 3-D solver and a transmission-line network simulation," IEEE Tran. EMC, Vol. 44, No. 2, pp. 309-317, May 2002.

[19] S. Atrous, D. Baudry, E. Gaboriaud, A. Louis, B. Mazari and D. Blavette, "Near-field investigation of the radiated susceptibility of printed circuit boards," Proc. of 2008 Int. Symp. on EMC Europe, Hamburg, Germany, 8-12 Sep. 2008.

[20] C. Leseigneur, P. Fernandez-Lopez, C. Arcambal, D. Baudry and A. Louis, "Near-field coupling model between electronic systems and transmission line," Proc. IEEE Int. Symp. EMC, Fort Lauderdale, FL, USA, pp. 22-27, 25-30 Jul. 2010.

[21] C.-N. Chiu and C.-C. Yang, "A solution for increasing immunity against the influence of ground variations on a board integrated GPS antenna", Progress In Electromagnetics Research (PIER) C, Vol. 15, pp. 211218, 2010 .

[22]E. R. Rajkumar, B. Ravelo, M. Bensetti, and P. Fernandez-Lopez, "Application of a hybrid model for the susceptibility of arbitrary shape metallic wires disturbed by EM near-field radiated by electronic structures," Progress In Electromagnetics Research (PIER) B 37, pp. 143-169, 2012.

[23]E. R. Rajkumar, B. Ravelo, M. Bensetti, Y. Liu, P. Fernandez-Lopez, F. Duval and M. Kadi, "Experimental study of a computational hybrid method for the radiated 
coupling modelling between electronic circuits and electric cable", International Journal of Advanced Engineering Technology (IJAET), Vol. 3, No. 1, pp. 115, Mar. 2012.

[24]Z. Song, S. Donglin, F. Duval, A. Louis and D. Fei, “A Novel Electromagnetic Radiated Emission Source Identification Methodology," Proc Asia-Pacific Symposium on EMC (APEMC), Pekin, China, April 12162010.

[25] D. Baudry, F. Bicrel, L. Bouchelouk, A. Louis, B. Mazari, and P. Eudeline, "Near-field techniques for detecting EMI sources," Proc. IEEE Int. Symp. on EMC, Santa Clara, CA, USA, Vol. 1, pp. 11-13, Aug. 2004.

[26] D. Baudry, L. Bouchelouk, A. Louis, and B. Mazari, "Near-field test bench for complete characterization of components radiated emission," Proc. EMC Compo 2004 conference, Angers, France, pp. 85-89, Apr. 2004.

[27]D. Baudry, C. Arcambal, A. Louis, B. Mazari and P. Eudeline, "Applications of the Near-Field Techniques in EMC Investigations," IEEE Tran. EMC, Vol. 49, No. 3, pp. 485-493, Aug. 2007.

[28] D. Baudry, A. Louis, and B. Mazari, "Characterization of the open ended coaxial probe used for near field measurements in EMC applications," Progress in Electromagnetics Research, PIER, Vol. 60, pp. 311333, 2006.

[29] Y. Vives-Gilabert, C. Arcambal, A. Louis, F. Daran, P. Eudeline and B. Mazari, "Modeling Magnetic Radiations of Electronic Circuits using Near-Field Scanning Method," IEEE Tran. EMC, Vol. 49, No. 2, pp. 391-400, May 2007.

[30] Y. Vives-Gilabert, C. Arcambal, A. Louis, P. Eudeline and B. Mazari, "Modeling Magnetic Emissions Combining Image Processing and an Optimization Algorithm," IEEE Tran. EMC, Vol. 51, No. 4, pp. 909918, Nov. 2009.

[31] P. Fernandez Lopez, A. Ramanujan, Y. Vives Gilabert, C. Arcambal, A. Louis, and B. Mazari, "A radiated emission model compatible to a commercial electromagnetic simulation tool," in Proc. of 20th Int. EMC Zurich Symp., pp. 369-372, Zurich, Switzerland, Jan. 2009.

[32] P. Fernández-López, C. Arcambal, D. Baudry, S. Verdeyme and B. Mazari, "Radiation Modeling and Electromagnetic Simulation of an Active Circuit," Proc. EMC Compo'09, Toulouse, France, Nov. 17-19 2009.

[33] P. Fernandez-Lopez, C. Arcambal, D. Baudry, S. Verdeyme, and B. Mazari, "Simple Electromagnetic Modeling Procedure: From Near-Field Measurements to Commercial Electromagnetic Simulation Tool," IEEE Tran. Instrum. Meas., Vol. 59, No. 12, pp. 3111-3120, Dec. 2010.

[34] C. E. Baum, "Emerging Technology for Transient and Broad-Band Analysis and Synthesis of Antennas and
Scaterrers," Interaction Note 300, Proc. of IEEE, pp. 1598-1616, Nov. 1976.

[35]R. Jauregui, M. Pous, M. Fernández and F. Silva "Transient Perturbation Analysis in Digital Radio," Proc. IEEE Int. Symp. EMC, Fort Lauderdale, Florida, USA, pp. 263-268, Jul. 25-30 2010.

[36] T. Ordas, M. Lisart, E. Sicard, P. Maurine and L. Torres, "Near-Field Mapping System to Scan in Time Domain the Magnetic Emissions of Integrated Circuits," Proc. PATMOS' 08: Int. Workshop on Power and Timing Modeling Optimization and Simulation, Ver. 111, 2009.

[37] W. Winter and M. Herbrig, "Time Domain Measurement in Automotive Applications," Proc. IEEE Int. Symp. EMC, Austin, Texas, USA, pp. 109-115, Aug. 17-21 2009.

[38] S. Braun, E. Gülten, A. Frech and P. Russer, "Automated Measurement of Intermittent Signals using a Time-Domain EMI Measurement System," Proc. IEEE Int. Symp. EMC, Austin, Texas (USA), pp. 232235, Aug. 17-21 2009.

[39] J. Rioult, D. Seetharamdoo and M. Heddebaut, "Novel Electromagnetic Field Measuring Instrument with RealTime Visualization," Proc IEEE Int. Symp. EMC, Austin, Texas (USA), pp. 133-138, Aug. 17-21 2009.

[40] D. D. Ebenezer and P. R. Stepanishen, "A wave-vectortime-domain technique to determine the transient acoustic radiation loading on cylindrical vibrators in an inviscid fluid with axial flow," The Journal of the Acoustical Society of America, Vol. 89, No. 1, pp. 3951, 1991.

[41]R. Rammal, M. Lalande, E. Martinod, N. Feix, M. Jouvet, J. Andrieu and B. Jecko, "Far Field Reconstruction from Transient Near-Field Measurement Using Cylindrical Modal Development", Int. J. Ant. Prop., Hindawi, Article ID 798473, 7 pages, Vol. 2009.

[42] S. P. Skulkin, "Near-field measurements in the time domain", Precision Electromagnetic Measurements Digest 1996, Braunschweig, Germany, pp. 428.

[43] T. Stadtler, L. Eifler and J. L. Ter Haseborg, "Double probe near field scanner, a new device for measurements in time domain," Proc of IEEE Int. Symp. EMC TU, Hamburg-Harburg, Hamburg, Germany, pp. 86-90, 1, Aug. 2003.

[44]R. Cicchetti, "Transient Analysis of Radiated Field from Electric Dipoles and Microstrip Lines," IEEE Tran. Ant. Prop., Vol. 39, No. 7, pp. 910-918, Jul. 1991.

[45] Y. Liu, B. Ravelo, P. Fernandez-Lopez, D. Baudry and J. Ben Hadj Slama, "Near-field/near-field transform in frequency domain with PWS method", Proc. 5th International Conference on Electromagnetic NearField Characterization and Imaging (ICONIC) 2011, Rouen, France, Nov. 30 - Dec. 22011.

[46] B. Ravelo, Y. Liu and J. B. H. Slama, "Time-Domain Planar Near-Field/Near-Field Transforms with PWS 
Method", Eur. Phys. J. Appl. Phys. (EPJAP), Vol. 53, No. 1, Feb. 2011, 30701-pp. 1-8.

[47] Y. Liu, B. Ravelo and J. B. H. Slama, "On the TimeDomain Near-Field Radiation with PWS Method", Proc. Advanced Electromagnetics Symposium (AES) 2012, Paris, France, April 16-19 2012.

[48]H. R. Hertz, "Untersuchungen ueber die Ausbreitung der Elektrischen Kraft," (in German) Johann Ambrosius Barth, Leipzig, Germany, 1892.

[49] C. E. Baum, "Some Characteristics of Electric and Magnetic Dipole Antennas for Radiating Transient Pulses," Sensor and Simulation Note 405, Jan. 71.

[50] B. K. Singaraju and C. E. Baum, "A Simple Technique for Obtaining the Near Fields of Electric Dipole Antennas from Their Far Fields," Sensor and Simulation Note 213, Mar. 76.

[51] J. Song and K.-M. Chen, "Propagation of EM Pulses Excited by an Electric Dipole in a Conducting Medium," IEEE Tran. Ant. Prop., Vol. 41, No. 10, pp. 1414-1421, 1993.

[52] Lakhtakiaa, V. K. Varadana and V. V. Varadana, "Time-Harmonic and Time-Dependent Radiation by Bifractal Dipole Arrays," Int. J. Electronics, Vol. 63, No. 6, pp. 819-824, Dec. 1987.

[53]H. G. Schantz, "Electromagnetic Energy around Hertzian Dipoles," IEEE Tran. Ant. Prop. Magazine, Vol. 43, No. 2, pp. 50-62, Apr. 2001.

[54] W. Jun-Hong, J. Lang and J. Shui-Sheng, “Optimization of the Dipole Shapes for Maximum Peak Values of the Radiating Pulse," Proc. IEEE Tran. Ant. Prop. Society Int. Symp., Vol. 1, pp. 526-529, 1997.

[55] V. I. Selin, "Asymptotics of the Electromagnetic Field Generated by a Point Source in a Layered Medium," Computational Mathematics and Mathematical Physics, Vol. 41, No. 6, pp. 915-939, 2001.

[56] W. C. Chew and J. A. Kong, "Electromagnetic field of a dipole on a two-layer earth," Geophysics, Vol. 46, No. 3, pp. 309-315, Mar. 1981.

[57] S. I. Smagin and V. N. Mazalov, "Calculation of the Electromagnetic Fields of Dipole Sources in Layered Media," Doklady Physics, Vol. 50, No. 4, pp. 178-183, Apr. 2005.

[58] J. C.-E. Sten and A. Hujanen, "Aspects on the Phase Delay and Phase Velocity in the Electromagnetic NearField," Progress In Electromagnetics Research (PIER), Vol. 56, pp. 67-80, 2006.

[59] J. Song and K.-M. Chen, "Propagation of EM pulses excited by an electric dipole in a conducting medium," IEEE Tran. Ant. Prop., Vol. 41, No. 10, pp. 1414-1421, 1993.

[60] A. Lakhtakiaa, V. K. Varadana and V. V. Varadana, "Time-harmonic and time-dependent radiation by bifractal dipole arrays," Int. J. Electronics, Vol. 63, No. 6, pp. 819-824, Dec. 1987.
[61] I. P. Kozlov, "Electromagnetic fields in planar-layered media close to a zero of the permittivity," J. Comm. Technol. Electron., Vol. 45, No. 5, pp. 496-502, 2000.

[62] M. Birsan, "Low-frequency transient (time domain) electromagnetic fields propagating in a marine environment," Int. J. Numerical Modelling, Devices and Fields, Vol. 17, No. 3, pp. 325-333, Apr. 2004.

[63] Y. Liu and B. Ravelo, "Calculation of Electrical Field from Magnetic Near-Field with PWS Method in TimeDomain", Proc. 16ème Colloque international sur la compatibilité électromagnétique (CEM2012), 25-27 Avril 2012, Rouen, France.

[64] Y. Liu, B. Ravelo, A. K. Jastrzebski, and J. Ben Hadj Slama, "Calculation of the Time Domain z-Component of the EM-Near-Field from the x-and y-Components", Proc. 41st European Microwave Conference (EuMC) 2011, Manchester, UK, Oct. 9-14 2011, pp. 317-320.

[65]B. Ravelo, "E-field extraction from H-near-field in time-domain by using PWS method," Progress In Electromagnetics Research (PIER) B, Vol. 25, pp. 171$189,2010$.

[66] B. Ravelo, Y. Liu, A. Louis and A. K. Jastrzebski, "Study of high-frequency electromagnetic transients radiated by electric dipoles in near-field", IET Microw., Antennas Propag., Vol. 5, No. 6, pp. 692 - 698, Apr. 2011.

[67] Y. Liu and B. Ravelo, "Near-field Map Radiated by Structures Disturbed by Arbitrary Transient Signals", Proc. Advanced Electromagnetics Symposium (AES) 2012, April 16-19 2012, Paris, France.

[68] B. Ravelo and Y. Liu, "Computation of Transient NearField Radiated by Electronic Devices from Frequency Data", Chap. 1, Fourier Transform Applications, Ed. by S. M. Salih, Published by Intech open science, Apr. 2012, Rijeka, Croatia, pp. 3-26.

[69] Y. Liu, B. Ravelo, and P. Fernandez-Lopez, "Modeling of Magnetic Near-Field Radiated by Electronic Devices Disturbed by Complex Transient Signals", Applied Physics Research (APR), Vol. 4, No. 1, Feb. 2012, pp. 3-18.

[70] C. A. Balanis, Antenna theory: Analysis and design, 3rd ed., Wiley, New York (USA), 2005.

[71] D. T. Paris, W. M. Leach and E. B. Joy, "Basic theory of probe-compensated near-field measurements," IEEE Tran. Ant. Prop., Vol. 26, No. 3, pp. 373-379, May 1978.

[72] J. J. H. Wang, "An examination of the theory and practices of planar near-field measurement," IEEE Tran. Ant. Prop., Vol. 36, No. 6, pp. 746-753, Jun. 1988.

[73] P. S. H. Leather and J. D. Parsons, "Plane wave spectra test-zone fields and simulation of antenna pattern measurements," Electronic Letters, Vol. 39, No. 25, pp. 1780-1782, Dec. 2003.

[74] J. Shi, M. A. Cracraft, J. Zhang and R. E. DuBroff, "Using Near-Field Scanning to Predict Radiated 
Fields," Proc. IEEE Ant. Prop. Int. Symp., San Jose, CA, USA, Vol. 3, pp. 1477-1480, 1989.

[75] J. Higashiyama, Y. Tarusawa, "Method for measuring radiated electric field excited by linear array antenna using near field to far field transformation," Proc. 18th Int. Zurich Symp. EMC, Munich, Germany, Sep. 24-28 2007, pp. 417-420.

[76] B. Ravelo, Z. Riah, D. Baudry and B. Mazari, "E-field extraction from $\mathrm{Hx}$ - and $\mathrm{Hy}$ - near field values by using plane wave spectrum method", Eur. Phys. J. Appl. Phys. (EPJAP), Vol. 53, No. 1, 11201-pp. 1-10, Jan. 2011.

[77] Agilent EEsof EDA, "Overview: Electromagnetic Design System (EMDS),” (2008, Sep.) [Online]. Available: http://www.agilent.com/find/eesof-emds

[78] Ansoft corporation, "Simulation Software: Highperformance Signal and Power Integrity," Internal Report, 2006.

[79] ANSYS, "Unparalleled Advancements in Signal- and Power-Integrity, Electromagnetic Compatibility Testing," (2009, Jun. 16) [Online]. Available: http://investors.ansys.com/

[80] North East Systems Associates (NESA), "RJ45 Interconnect Signal Integrity," (2010 CST Computer Simulation Technology AG.) [Online]. Available: http://www.cst.com/Content/Applications/Article/Articl e.aspx?id=243

[81] H. Xie, J. Wang, R. Fan, and Y. Liu, "Spice models for radiated and conducted susceptibility analyses of multiconductor shielded cables," Progress In Electromagnetics Research (PIER) 103, pp. 241-257, 2010.

[82] M. Adada, "High-Frequency Simulation TechnologiesFocused on Specific High-Frequency Design Applications," Microwave Engineering Europe, pp. 1617, Jun. 2007.

[83]R. S. Edwards, A. C. Marvin and S. J. Porter, "Uncertainty Analyses in the Finite-Difference TimeDomain Method," IEEE Tran. EMC, Vol. 52, No. 1, pp. 155-163, Feb. 2010.

[84]L. Liu, X. Cui and L. Qi, "Simulation of Electromagnetic Transients of the Bus Bar in Substation by the Time-Domain Finite-Element Method," IEEE Tran. EMC, Vol. 51, No. 4, Nov. 2009, pp. 1017-1025.

[85] R. Jauregui, P. I. Riu and F. Silva "Transient FDTD Simulation Validation," Proc IEEE Int. Symp. EMC, Fort Lauderdale, Florida, USA, pp. 257-262, Jul. 25-30 2010.

[86] B. Shanker, M. A. Lu, A. Ergin and E. Michielssen, "Plane-wave time-domain accelerated radiation boundary kernels for FDTD analysis of 3D electromagnetic phenomena," IEEE Tran. Ant. Prop., Vol. 53, No. 11, pp. 3704-3716, Nov. 2005.

[87] Y. Liu, "Study of electronic circuit radiated near-field emissions in time-domain," PhD Thesis, IRSEEM/ESIGELEC, Univ. Rouen, France, 2012. 